NBER WORKING PAPER SERIES

THE IMPACT OF UNCERTAIN INTELLECTUAL PROPERTY RIGHTS ON THE MARKET FOR IDEAS: EVIDENCE FROM PATENT GRANT DELAYS

\author{
Joshua S. Gans \\ David H. Hsu \\ Scott Stern \\ Working Paper 13234 \\ http://www.nber.org/papers/w13234 \\ NATIONAL BUREAU OF ECONOMIC RESEARCH \\ 1050 Massachusetts Avenue \\ Cambridge, MA 02138 \\ July 2007
}

We thank Nisvan Erkal, Thomas Hellmann, Guido Imbens, Ben Jones, Josh Lerner, Manju Puri, Jennifer Reinganum, Chris Taber, Marie Thursby, John van Reenen, and Ralph Winter, and seminar participants at various universities and conferences, for comments and discussion. We acknowledge funding support from the Mack Center at Wharton, the Intellectual Property Research Institute of Australia and the Australian Research Council. The views expressed herein are those of the author(s) and do not necessarily reflect the views of the National Bureau of Economic Research.

(C) 2007 by Joshua S. Gans, David H. Hsu, and Scott Stern. All rights reserved. Short sections of text, not to exceed two paragraphs, may be quoted without explicit permission provided that full credit, including $\odot$ notice, is given to the source. 
The Impact of Uncertain Intellectual Property Rights on the Market For Ideas: Evidence From

Patent Grant Delays

Joshua S. Gans, David H. Hsu, and Scott Stern

NBER Working Paper No. 13234

July 2007

JEL No. L24,L26,O32,O34

\begin{abstract}
This paper considers the impact of the intellectual property (IP) system on the timing of cooperation/licensing by start-up technology entrepreneurs. If the market for technology licenses is efficient, the timing of licensing is independent of whether IP has already been granted. In contrast, the need to disclosure complementary (yet unprotected) knowledge, asymmetric information, or search costs may retard efficient technology transfer. In these cases, reductions in uncertainty surrounding the scope and extent of IP rights may facilitate trade in the market for ideas. We employ a dataset combining information about cooperative licensing and the timing of patent allowances (the administrative event when patent rights are clarified). While pre-allowance licensing does occur, the hazard rate for achieving a cooperative licensing agreement significantly increases after patent allowance. Moreover, the impact of the patent system depends on the strategic and institutional environment in which firms operate. Patent allowance seems to play a particularly important role for technologies with longer technology lifecycles or that lack alternative mechanisms such as copyright, reputation, or brokers. The findings suggest that imperfections in the market for ideas may be important, and that formal IP rights may facilitate gains from technological trade.
\end{abstract}

Joshua S. Gans

University of Melbourne

200 Leicester Street

Carlton VIC 3035

Australia

J.Gans@mbs.edu

David H. Hsu

2000 Steinberg-Dietrich Hall

Wharton School, University of Pennsylvania

Philadelphia, PA 19104

dhsu@wharton.upenn.edu
Scott Stern

Management and Strategy Department

Kellogg School of Management

2001 Sheridan Road

Evanston, IL 60208

and NBER

s-stern2@northwestern.edu 


\section{Introduction}

The commercialization of innovation often depends on transferring the knowledge and technology underlying an innovation from the original inventor to a firm able to effectively develop that innovation for the market (Teece, 1986; Arora et al., 2001). The gains from technological trade may include reductions in the costs associated with translating an idea into a commercially viable product and enhancing specialization by firms into knowledge production or commercialization (Arora et al., 2001). Imperfections in the market for technology may significantly reduce the gains from technological trade. Potential licensors may limit information disclosure in order to avoid expropriation by potential partners (Arrow, 1962; Anton and Yao, 1994), particularly when knowledge disclosure requires effort on the part of the licensor (Arora, 1995). Moreover, matching in the market for technology may depend on a costly search process, limiting technology partnerships (Hellmann, 2005).

This paper evaluates the role that formal intellectual property (IP) rights, most notably patents, play in facilitating technology transfer between firms in the market for ideas (Kitch, 1977; Nelson and Merges, 1990; Arora, 1995; Arora et al., 2001; Gans et al., 2002). We focus on how the IP system impacts the timing of cooperation between start-up technology entrepreneurs and established firms during commercialization. Building on studies of the operation of the patent system (Cohen and Merrill, 2003; Jaffe and Lerner, 2004), we empirically exploit a fundamental feature of the patent system: patent grant delay. While most analyses implicitly assume that once an invention is developed, IP rights are granted and enforced, both the grant of IP rights and the achievement of cooperation take place over time. When licensing occurs, it takes place in one of two institutional regimes: a pre-patent period in which the scope and timing of rights is uncertain, or a post-patent period in which uncertainty about the scope of IP rights has been narrowed. Start-up innovators pursuing a cooperative commercialization strategy face a crucial dynamic tradeoff: while an early agreement enhances productive efficiency (and reduces time-to-market), later agreements may be associated with greater bargaining power and more effective technology transfer. We contend that the timing of cooperation is, therefore, a key strategic choice, and the optimal timing of 
cooperation depends on the commercialization environment in which the firm operates. ${ }^{1}$

To explore how the business environment shapes commercialization dynamics, we focus on the moment at which the rights to be granted by the USPTO are announced to the patent applicant, the Notice of Patent Allowance event ("patent grant" follows several months later). The identification strategy exploits the significant empirical variation in patent allowance and licensing lags across technologies, and the timing of licensing relative to patent allowance. Using a novel dataset of technologies developed by start-up innovators and ultimately commercialized through cooperation, we link the timing of cooperative licensing with the timing of patent allowance. We examine whether the hazard rate for cooperation changes in response to a change in the commercialization environment (the mitigation of uncertainty resulting from patent allowance), and how the impact of patent allowance depends on firm, technology and industry characteristics. By studying how the timing of cooperation is influenced by the timing of patent allowance, we provide evidence of the causal influence of the IP system on the market for ideas.

Our findings indicate that patent allowance substantially increases the hazard rate of achieving a licensing agreement (a 70-80\% increase in the licensing hazard), and this effect is most pronounced in the time period immediately following the patent allowance event. The overall rate of licensing and the salience of patent allowance on the licensing hazard rate are associated with measures of the strategic and institutional environment in which firms operate. For technologies where productive efficiency effects are important, the overall rate of licensing is more rapid. For technologies with alternative IP rights available (such as copyright) or firms in locations where information brokers and reputational mechanisms may be important (such as Silicon Valley), the impact of patent allowance on the licensing hazard rate is reduced. We are cautious in our interpretation, however, as the sample size is modest and the analysis is conditioned on a sample of firms for which licenses are observed.

\section{Probabilistic Patents}

Recent research on the impact of the patent system on technology entrepreneurship emphasizes

\footnotetext{
${ }^{1}$ Only a few studies consider licensing timing (Katila and Mang, 2003; Dechaneaux et al., 2003; Elfenbein, 2005), and these do not focus on the role of patent grant delay in start-up commercialization.
} 
the potential role of intellectual property in facilitating commercialization through the market for ideas (e.g., Nelson and Merges, 1990; Anand and Khanna, 2000; Arora et al., 2001; Gans et al., 2002). In the absence of formal intellectual property, start-up innovators seeking commercialization partners may be subject to expropriation (Arrow, 1962; Anton and Yao, 1994). At the same time, efficient commercialization often requires contracting with more established partners in control of key complementary assets (Teece, 1986). Formal intellectual property rights may enable technology transfer by reducing the potential for expropriation, thereby increasing the incentives for knowledge disclosure and technology contracting. This perspective on the patent system assumes that the operation of the patent system is efficient and involves an unambiguous administrative process: patents are granted in a timely manner and are associated with well-defined property rights conferring significant competitive advantage. However, recent research on the operation of the patent system and patent enforcement has emphasized that patents are "probabilistic" property rights (Lemley and Shapiro, 2005). To the extent that IP rights are probabilistic, uncertainty may have implications for technology contracting. As discussed in Section 3, specific types of uncertainty may limit opportunities for efficient contracting and shift the timing of cooperative commercialization. It is, therefore, useful to distill the distinct types of uncertainty over patent rights: patent allowance, patent scope, patent grant delay, patent enforceability, and patent value.

Patent grant uncertainty. A crucial source of potential uncertainty in the patent system could be whether a patent applicant is likely to receive any patent rights. While the formal structure of the patent system suggests a high degree of uncertainty over patent grant, recent empirical research on the US and EU patent systems suggest that most patent applications are granted in some form. Accounting for “continuing patent applications" (which allow applicants to revise their applications over time), the US grant rate may be as high as 90 percent (Quillen and Webster, 2001; Graham and Harhoff, 2006). The key moment at which the uncertainty over grant is resolved is the Notice of Allowance. When inventors receive this Notice, the claims that will be granted are specified. ${ }^{2}$ While the Notice of Allowance

2 See www.uspto.gov/web/offices/pac/mpep/documents/1300 1303.htm\#sect1303: "The application identified above has been examined and is allowed for issuance as a patent. Prosecution on the merits is closed." (underlined in 
mitigates uncertainty over allowed claims, it reduces but does not eliminate more pervasive sources of uncertainty, such as the ultimate patent scope, or the costs and probability of enforcement.

Patent scope uncertainty. While most patent applicants are granted a patent in some form, significant uncertainty exists over the scope of the patent rights ultimately allowed and the enforceability of allowed claims through litigation. ${ }^{3}$ The heart of the patent examination process involves repeat negotiations and correspondence between a patent applicant and the patent examiner over the allowance of particular patent claims, or the wording of those claims (Cohen and Merrill, 2003). This uncertainty of patent scope prior to allowance increases the costs of specifying a technology license (Lerner and Merges, 1998). Moreover, pre-allowance contracts often require complex contingent clauses (one of our practitioner interviews said: "royalty rate $\mathrm{r}$ applies if Claim \#x is allowed, while royalty rate $\mathrm{r}$ ' applies if Claim \#x is disallowed"). As noted by Heller and Eisenberg (1998), "Although US patent law does not recognize enforceable rights in pending patent applications, firms and universities typically enter into license agreements before the issuance of patents, and firms raise capital on the basis of the inchoate rights preserved by patent filings... each potential patent creates a specter of rights that may be larger than the actual rights...conferred by the PTO.” Patent allowance not only reduces patent scope uncertainty, but also reduces information asymmetry between applicants and potential licensees (applicants have detailed information about interactions with the examiner and likely patent scope). Of course, uncertainty over patent scope is not fully resolved until "the last court speaks," requiring significant (endogenous) investment and time (Lanjouw and Schankerman, 2001; Lemley and Shapiro, 2005).

Patent pendency uncertainty. Though most research on the patent system implicitly assumes that patent application and grant are coincident (or are, at best, an administrative matter), patent application lags are long and variable. According to Popp et al. (2004), the average patent grant lag (inclusive of

the original and accessed 11/15/06). The Notice specifies issue and publication fees, deadlines, and the process of readying the patent for formal grant. We focus on the Notice of Allowance date (rather than the traditional patent grant date) since this is when uncertainty over allowed claims is resolved. We adopt the term "allowance" rather than "grant," except where we discuss studies or phenomena focusing on the patent grant event per se.

${ }^{3}$ Examiners produce "office actions" (interim decisions regarding applications) providing information that "may be useful in aiding the applicant to judge the propriety of continuing the prosecution of his/her application...few applications are allowed as filed." (http://www.uspto.gov/web/offices/pac/doc/general/index.html\#office). 
provisional applications and patent continuance) is 28 months, with a standard deviation of 20 months. Variation in patent grant delay seems to be driven by idiosyncratic factors: even with detailed controls, only $10 \%$ of the overall variance in patent grant delay is explained by observable factors, and the most important factors seem to be broad differences across technological fields (Popp et al., 2004). ${ }^{4}$ Patent pendency (and idiosyncratic variance in the process) has important implications for the timing of technology licensing: while licensors may be able to reduce transactional costs and enhance the value of licenses realized after patent allowance, innovators face significant opportunity costs if they delay commercialization while applications are pending.

Patent enforcement uncertainty. While the end of patent pendency mitigates certain uncertainties such as the variability of allowed claims, significant uncertainty remains concerning the ability to enforce those claims through the legal system. As emphasized by Lemley and Shapiro (2005), the uncertainty associated with litigation implies that patent grants are best characterized as probabilistic rights. It is useful, however, to distinguish how the nature of uncertainty changes after the allowance date. First, whereas the uncertainty arising during the pre-grant period involves significant information asymmetries between the applicant and potential licensees (since external parties may not have access to the complete record of "office actions" or even more informal interactions with patent examiners), the uncertainties associated with litigation are symmetric: both parties are on (roughly) equal footing in evaluating the allowed claims and their likelihood to survive court scrutiny. Second, whereas the uncertainty arising in the pre-grant period is systematic (no applicant can avoid the uncertainties associated with the patent application process), the resolution of uncertainty over validity claims and the enforcement of damages is endogenous to the litigation and negotiation strategies of patent holders and potential infringers. As Farrell and Shapiro (2007) argue, there are many cases where the incentives to litigate are low (or even negative), even in the absence of the transaction costs associated with litigation. Given that patent

\footnotetext{
${ }^{4}$ A recent literature debates the relationship between patent grant lags and the importance of the innovation. While Johnson and Popp (2003) suggest that more important innovations (as proxied by forward citations) are associated with more important innovation, Harhoff and Wagner (2005) find the reverse correlation using EU patent data. See Popp et al. (2004)
} 
litigation is expensive (compared to the relatively modest costs of patent application) it is not surprising that relatively few patents are litigated to a final judicial resolution: most patents never confront a full judicial review of their underlying validity or their legal scope (Lanjouw and Schankerman, 2001).

Uncertainty over market value. Finally, even if the legal uncertainty associated with patents was completely resolved, the economic and strategic value of patents is subject to a high degree of uncertainty. Patents vary widely in their value, which depends on endogenous outcomes in technology and product markets. For example, very few of the patented innovations in the biopharmaceutical industries are ultimately commercialized, and it is difficult to distinguish between different candidate drugs prior to the clinical trial process. The value of patent rights is thus probabilistic and can best be understood in terms of option value. While most patents confer limited returns to the innovator, a small fraction of patented innovations yields very high returns (Arora et al., 2003 and references therein).

\section{Patent Grant Delay and Frictions in the Markets for Ideas}

When the market for technology transfer functions well, efficient trades occur and, moreover, they occur in a timely manner (Arora et al., 2001). Put simply, the "sale" of an idea allows an innovation to be commercialized more quickly, yielding gains in productive efficiency, and so delays in the timing of cooperative agreements reflect a lost opportunity for maximizing the welfare gains from ideas trading. This section considers the potential drivers of delays in the licensing process and the dynamic interplay between patent grant timing and the timing of cooperative agreements. Our objective is not to develop a comprehensive model of the determinants of license timing; instead, our objective is to concisely illustrate (a) why the patent allowance date will not matter in the absence of market imperfections in the market for ideas, and (b) how the presence of market imperfections implies a dependence between the patent allowance date and the timing of technology licensing. In so doing, we seek to identify the impact of the operation of the patent system on the efficiency of the market for ideas.

The frictionless benchmark. Before turning to the impact of specific market imperfections, we begin by considering a "frictionless" environment to establish a benchmark for efficient trade in the market for ideas. Consider a stylized representation of the innovation commercialization process depicted 
in Figure A. There are three distinct phases. After an initial invention or prototype is developed, the technology entrepreneur files a patent application. Following a patent application there is a waiting stage during which there is uncertainty over patent scope and indeed whether it will be granted at all. Patent allowance (taken here as synonymous with the grant date) ${ }^{5}$ reduces this uncertainty but does not resolve it because infringement may still occur, and defending against it may be costly and uncertain.

Consider the interactions between a single potential "customer" for an invention $(C)$ to whom the research firm $(R)$ might license (as in Aghion and Tirole, 1994). Both parties are risk neutral. ${ }^{6}$ The potential commercial value of the invention to $C$ is $v$. For a frictionless market, we assume that: (1) there is symmetric information between $C$ and $R$ regarding $v$ and any other aspect of the patenting process; (2) $C$ and $R$ know of each other's existence from the outset (that is, $R$ faces no search costs) and (3) but for the knowledge contained in the patent application, $C$ has the necessary knowledge and resources to realize the value of the innovation. This last assumption implies that expropriation concerns are limited to knowledge which is potentially patentable, and that there is no specific human capital or tacit knowledge (in the sense of Arora, 1995) that must be drawn upon or otherwise disclosed for $C$ to make full use of the invention. Below, we relax each of these assumptions to demonstrate the impact of frictions and market imperfections on the market for ideas.

A lengthy patent process implies that it will take, say, $T$ periods from the time of application until the time a patent is allowed. ${ }^{7}$ In addition, there is uncertainty as to the scope of the potential patent, which will impact a pre-patent agreement. With probability $p$, a patent is granted with broad scope (and with probability 1- $p$ with narrow scope). For concreteness, we define a patent with broad scope as one which is very difficult to "invent around", while a narrow patent is essentially unenforceable (either $C$ or other firms will be able to invent around the formal intellectual property). Narrow patent scope not only reduces $R$ 's returns on the innovation, but can also impact $C$ 's returns as well (under narrow scope, the value of

\footnotetext{
${ }^{5}$ The lag between allowance and grant varies and is subject to some uncertainty. While this could be incorporated with additional notation, it would not change the main result or our hypotheses.

${ }^{6}$ Introducing risk aversion will create incentives to share risk among firms, which reinforces the incentives for early cooperation. We do not pursue this extension here, as we do not address this issue in our empirical work.

${ }^{7}$ Patent grant delay is itself uncertain. Adding this additional uncertainty would only strengthen our results.
} 
the innovation to $C$ will be $\underline{v}<v$ ). Note that both $v$ and $\underline{v}$ are expected returns conditional on broad versus narrow patent scope. This is due to the possibility of residual uncertainty from both commercial opportunities and the robustness of the patent claims in any subsequent litigation that might arise. Note that patent scope is distinct from patent validity, as patent grants do not establish validity (they instead grant the right to litigate). A patent is not valid until the "last court" speaks - and so patent awards reduce but do not eliminate patent scope and validity uncertainty (Lemley and Shapiro, 2005). ${ }^{8}$

As the firms are risk neutral, we consider licensing agreements whereby $R$ assigns any patent rights to $C$ for a flat fee. ${ }^{9}$ License agreements may be negotiated at either time 0 or $T$. If an agreement is signed at time 0 (for a fee, $t_{0}$ ), it is binding throughout the pre- and post-patent phases. If no agreement is signed, another opportunity to come to an agreement occurs at time $T$. Let $E[v] \equiv p v+(1-p) \underline{v}$. By signing an agreement at time $0, C$ gets $\left(1-\delta^{T}\right) v+\delta^{T} E[v]$ while $R$ gets paid immediately. If no agreement is signed, then a license agreement is negotiated at $T$ (for a fee, $t_{T}$ ) following the reduction in patent scope uncertainty. ${ }^{10}$ If scope is narrow, $C$ can realize the commercial value of the innovation without an agreement $\left(t_{T}=0\right)$. We assume that the negotiators are able to achieve a cooperative outcome (i.e., firms "maximize" and split the surplus evenly). ${ }^{11}$ At $T$, if patent scope is wide, $t_{T}=\frac{1}{2} v$, while if patent scope is narrow, $t_{T}=0$. If we suppose that commercialization is not feasible until a licensing agreement is signed, if the firms wait, the expected licensing fee at time 0 is $p \frac{1}{2} v$ with $R$ 's expected return being $\delta^{T} p \frac{1}{2} v$ and $C^{\prime}$ 's being $\delta^{T}\left(p \frac{1}{2} v+(1-p) \underline{v}\right)$. Based on these expected returns, there is always a joint gain for $C$ and $R$ to sign an agreement at time 0 . The joint expected returns from an agreement at time $T$ are $\delta^{T} E[v]$ while

\footnotetext{
${ }^{8}$ We thank the editorial reviewers for bring up this point. See Farrell and Shapiro (2007) for further discussion.

${ }^{9} \mathrm{C}$ might make payment to $R$ contingent upon realized patent scope, a contingent fee. For the results that follow, allowing for contingent fees or royalty payments would make little difference, even in the market friction case.

${ }^{10}$ We assume that until $T$, only $R$ and $C$ can utilize the innovation and so sustain higher returns of $v$ for that period. Allowing additional pre-grant imitators would reduce pre-patent returns but does not change the comparative statics.

${ }^{11}$ This is the Nash bargaining outcome assuming that parties have equal bargaining power. Gans and Stern (2000) develop non-cooperative foundations for this bargaining assumption in the context of a licensing game where the timing of agreement is endogenous (although that model implicitly assumes that a patent has already been granted).
} 
an agreement at time 0 will jointly yield $\left(1-\delta^{T}\right) v+\delta^{T} E[v]$, a gain of $\left(1-\delta^{T}\right) v$. It is beneficial for the parties to agree earlier regardless of the uncertainty over scope. The 'price' agreed to at that time will reflect the differing impacts of patent scope uncertainty on $R$ and $C$. Since firms split the surplus evenly:

$$
\underbrace{t_{0}-\delta^{T} p \frac{1}{2} v}_{\substack{R \text { s surplus from an earlier } \\
\text { rather than later agreement }}}=\underbrace{\left(1-\delta^{T}\right) v+\delta^{T} E[v]-t_{0}-\delta^{T}\left(p \frac{1}{2} v+(1-p) \underline{v}\right)}_{\begin{array}{c}
C \text { s surplus from an earlier } \\
\text { rather than later agreement }
\end{array}} \Rightarrow t_{0}=\frac{1}{2}\left(1-\delta^{T}(1-p)\right) v
$$

In this case, $C$ 's expected return is $\frac{1}{2}\left(1-\delta^{T}(1-p)\right) v+\delta^{T}(1-p) \underline{v}$. It is useful to observe that $R^{\prime}$ 's return through licensing is increasing in $p$, since this enhances the expected value of the innovation. In a frictionless environment, license timing is driven solely by productive efficiency. To be sure, uncertainty over IP rights impacts the distribution of returns between the parties: as the likelihood of stronger patent protection increases, $R$ earns relatively more than $C$. However, in the absence of frictions in the market for ideas, the patent grant allowance does not impact the timing of technology licensing.

The case of frictions. While delay and uncertainty has no impact on the timing of technological trade in the baseline model, barriers to exchange in the market for ideas can induce a dependency between the patent allowance date and the timing of cooperative agreements. We focus on frictions which not only reduce the ability to achieve efficient trade but for which the reduction of uncertainty over patent scope serves to spur technological trade, including asymmetric information, search costs, and the ability of potential licensors to expropriate knowledge which is disclosed but unprotected by IP rights.

Consider the role of information asymmetries. The licensor may possess a number of different types of advantaged information, from information about the overall value of the license (and in which contingencies the innovation might be valuable) or the timing and/or scope of the rights to be allowed. Asymmetric information (from whatever source) leads to the potential failure to achieve a productively efficient agreement. Even when productively efficient technology exchanges would be jointly efficient, if potential licensors cannot credibly signal the value of their innovation (relative to the distribution of 
quality types), the market for ideas can break down. ${ }^{12}$ If the source of asymmetric information is unrelated to the information resolved by patent grant, the mere allowance of a patent will not alleviate this breakdown in technological trade. However, if the asymmetric information between the licensor and potential licensees relates, in part, to the probability that a patent will receive narrow (rather than broad) scope (i.e., differences in the value of $p$ ), or the precise nature of the claims that are likely to be allowed, then the clarification of those rights may spur market exchange. By waiting until IP rights are clarified, those who are likely to receive broad protection (relative to the expectations of potential licensees) are able to earn a licensing premium. When the patent allowance reduces the degree of asymmetric information (or, equivalently, allows for more efficient sorting of technologies), at least some potential licensors will delay cooperative commercialization until the uncertainty of patent scope is resolved.

A second mechanism resulting in a dependency between patent grant and the timing of cooperation arises from the presence of search costs. If the innovator has to engage in costly search to locate the most suitable commercialization partner, the incentives to search may only be sufficient after a patent (with broad scope) has already been allowed (Hellmann, 2005). Suppose that the cost of finding a partner is a fixed cost, $f$, in which $R$ can locate a customer, $C$, who would value the innovation $\Delta$ greater than the baseline of $v$ or $\underline{v}$, and that once $f$ is sunk, an agreement with this high-valuation partner is immediately feasible. On the one hand, locating a partner at time 0 increases $R$ 's returns by $\frac{1}{2}\left(1-\delta^{T}(1-p)\right) \Delta$. However, if $R$ waits until the patent is granted at $T$, the search will only be undertaken if the patent scope is broad, and its returns from search would be $\frac{1}{2} \Delta$. If $\frac{1}{2}\left(1-\delta^{T}(1-p)\right) \Delta<f \leq \frac{1}{2} \Delta$, then $R$ will be willing to search at $T$ but unwilling to search at time 0 . Moreover, the returns from time 0 agreement stay constant, while the returns from a time $T$ agreement will be increased to $\delta^{T} p\left(\frac{1}{2}(v+\Delta)-f\right)$. Therefore, if $\frac{1}{2}\left(\Delta-\frac{1-\delta^{T}}{p \delta^{T}} v\right) \geq f$, then $R$ will prefer to delay

\footnotetext{
${ }^{12}$ There is some analysis of this in the literature on patent licensing (e.g., Anton and Yao, 1994) but it focuses on achieving agreements in the face of information asymmetry rather than timing per se. A related literature on bargaining under asymmetric information provides a motivation for inefficient delay (Ausubel et al., 2002).
} 
search. Since the returns to search are higher when patent scope is known to be broad, search costs may induce delay until uncertainty over patent scope is resolved.

A third mechanism - and perhaps the most important - arises from the ability of licensees to expropriate knowledge that is disclosed by the licensor but unprotected by intellectual property. The potential for expropriation can significantly limit information disclosure by licensors (Arrow, 1962; Anton and Yao, 1994), particularly when knowledge disclosure requires effort on the part of the licensor (Arora, 1995). As emphasized in the baseline model, the mere presence of unprotected knowledge has no impact on the timing of cooperative licensing (though it will have a significant impact on the division of rents). However, establishing patent rights scope can have a significant impact on the risk of expropriation and the willingness of licensors to disclose unprotected information. While it may be difficult to predict the impact of unpatentable knowledge disclosure during the pre-grant period, start-up innovators may be able to tailor their disclosures to avoid expropriation in the event of bargaining breakdown once the scope of rights is clarified. For example, prior to patent grant, non-disclosure agreements with potential partners may be difficult (if not impossible) to write with any degree of precision or potential for enforcement; after a patent is granted, the costs and complexity of such contracts may decrease significantly. To the extent that the clarification of formal property rights reduces the risk of knowledge leakage, patent allowances may spur participation in the market for ideas.

The role of the strategic disclosure of unprotected complementary knowledge will be particularly important when such disclosures require effort on the part of the licensor (Arora, 1995). ${ }^{13}$ Suppose we reinterpret $\Delta$ in the search model above as the additional value that comes through knowledge transfer and $f$ as $R$ 's effort in facilitating that transfer. It may be difficult to contract on the supply of effort. Even if the outcome and costs of such transfer $(\Delta, f)$ are observable to both parties, it may be unverifiable to a third party (such as a judge) and so any agreement may not be enforceable. In this case, whether knowledge is

\footnotetext{
${ }^{13}$ As Arora (1995) emphasizes, "[t]echnology licensing involves more than just the permission to use the knowledge covered by patents: In many cases, the information required for successful utilization extends even beyond blueprints, drawings, and specifications and includes heuristics, rules of thumb, and other 'tricks of the trade."'
} 
transferred will depend upon $R$ 's incentives to do so. ${ }^{14}$ As in the search model, the primary issue is whether the reduction in uncertainty afforded by the patent allowance increases the gains from trade from cooperative commercialization evaluated at that point as compared to a prior time period. Using a similar analysis to the search model, if $\frac{1}{2}\left(1-\delta^{T}(1-p)\right) \Delta<f \leq \frac{1}{2} \Delta$, then $R$ will be willing to transfer knowledge at $T$ but will be unwilling to do so at time 0 . Thus, by waiting, the gains from trade rise by $p \delta^{T}(\Delta-f)$. However, the opportunity cost of that delay is $\left(1-\delta^{T}\right) v$. So if $\Delta-\frac{1-\delta^{T}}{p \delta^{T}} v>f$, delay will occur. ${ }^{15}$

Intuitively, while the incentives to disclose tacit knowledge after a licensing agreement has been signed are limited (the licensee will simply expropriate the value of any such disclosures), there may be significant incentives to disclose complementary tacit knowledge prior to the realization of a cooperative agreement. If disclosing such knowledge raises the value of the patentable portion of the innovation to potential licensors (while maintaining the relative bargaining position of licensee and licensor), then the willingness-to-pay by $C$ will be increasing in the effort devoted to disclosure by $R$. Moreover, since the additional value created by knowledge disclosure depends on the value of the patentable knowledge, the total incentives and equilibrium level of disclosure will depend on whether patent scope is known to be broad or whether patent rights remain uncertain. When the value arising from broad patent rights are sufficiently high and the "boost" from complementary knowledge disclosure is sufficiently steep, both licensors and licensees may delay licensing negotiations until patent allowance in order to maximize the innovator's incentives to transfer tacit knowledge.

Empirical implications. Market frictions - barriers to efficient technological trade - can induce a systematic relationship between the patent grant process and the timing of technology licensing. While information asymmetries, search costs, and expropriation risks may limit technological trade prior to the receipt of a patent, the reduction of uncertainty resulting from patent grant can trigger trade in the market

\footnotetext{
${ }^{14}$ This framing is consistent with Lowe's (2004) formulation of licensing when a great deal of knowledge is tacit.

${ }^{15}$ There is a key difference between the search and knowledge transfer models. In the search model, delay is driven by $R$ 's own incentives, while in the knowledge transfer model, if trade delay results in losses, $C$ would have the ability to compensate $R$ for any loss in its bargaining position that comes from delay. Hence, delay is more likely (given the same parameter values) in the knowledge transfer model relative to the search model.
} 
for ideas. Conversely, without frictions, there should be no systematic relationship between patent allowance and the timing of cooperative agreements. This insight holds several testable implications.

First, the relative importance of productive efficiency and barriers to technological exchange will differ across technologies. As such, the incentives for early licensing and the benefits from delay until patent rights are clarified will vary across innovations. Moreover, one might expect that this variation will be narrower within a given industry than across industries. For example, most software products are associated with relatively short product lifecycles, and so the benefits from productive efficiency are likely quite high in this sector. In addition, software patents are thought by some to be susceptible to being "low quality" and held invalid if challenged (Hall and MacGarvie (2006) and references therein). Conversely, studies of the "patent thicket" in the semiconductor industry (Shapiro, 2001) suggest significant barriers to efficient technological trade (and the ability of enforceable IP rights in reducing those barriers) in those sectors. So both pre-allowance and post-allowance licensing agreements will be observed in equilibrium, and the propensity for pre-grant and post-grant licensing will vary by industry and other observable characteristics of the technology and innovator. Second, if barriers to technological exchange limit early licensing, clarification of patent rights reduces the frictions in the market for ideas and so raise the incentives to achieve a cooperative agreement. As a result of these enhanced incentives, the equilibrium impact of patent allowance will be to raise the hazard rate of achieving a licensing agreement. Relative to a baseline pattern of the timing of cooperation, patent allowances are predicted to be associated with a "boost" in licensing.

Third, the theoretical framework suggests that after the scope of IP rights is clarified, productive efficiency considerations provide incentives for firms to achieve a licensing agreement as soon as possible. Thus, for firms seeking a licensing partner as part of the commercialization process, licensing will tend to take place immediately after the patent allowance date. A higher hazard of licensing immediately following the patent allowance date provides evidence for both the existence of frictions in the market for ideas and for the value of formal IP rights in facilitating cooperative technology transfer. Finally, patent allowance importance depends upon the strategic environment in which the firm operates. The clustering of licensing after the patent allowance date results from the strategic choice by firms to wait for the clarification of uncertainty (and is balanced against a desire for productive efficiency). The 
impact of patent allowance will thus be relatively unimportant in environments where productive efficiency is particularly important, such as industrial sectors with short product life cycles (such as the software industry). Also, the impact of patent allowance will be muted in environments where the impact of frictions is modest. For example, in locations or industries in which alternative institutional arrangements may provide a substitute for formal IP rights, the impact of patent allowance on the hazard rate of licensing will be reduced. As such, the framework predicts that the impact of patent allowance will be lower for firms with access to rich "knowledge broker" networks, such as those located in Silicon Valley or those who are affiliated with networked venture capitalists (e.g., Saxenian, 1994).

\section{Data}

Our data are drawn from a sample of more than 200 technology licensing deals announced between 1990 and 1999, and appearing in the Security Data Corporation (SDC) database. Our sample allows us to focus on the timing of licensing relative to changes in the IPR environment for a sample of technologies which seek and receive patent protection and for which a licensing outcome is realized. For each deal, we gathered the license date announcement, the deal industry sector, and firm location and age information. For each patent-license pair, we then collected detailed patent information from the USPTO and the NBER patent data file (Hall et al., 2001), and VC financing information from the Venture Economics database. After trimming the dataset to focus on an unambiguous set of patent-license pairs between start-up innovators and downstream firms, the final dataset consists of 198 observations across four industry sectors (more details of the sampling scheme are contained in Appendix A).

Variable definitions and summary statistics. Table 1 reports variable definitions and summary statistics for each of the timing measures, and patent and firm characteristics. Each of the timing measures is calculated relative to the patent application date. Patent application date is the date of first patent application for a given technology, inclusive of continuances, divisions, and provisional applications. ${ }^{16}$ We investigate two timing measures linked to the reduction in uncertainty resulting from administrative actions on the part of the patent office. Patent allowance date is the date on which the USPTO sends a

\footnotetext{
${ }^{16}$ Our results are also robust to use of the "final" application date.
} 
Notice of Patent Allowance to the patent applicant, at which point the "prosecution on the merits is closed" (see footnote 3). From the perspective of our theoretical framework, the patent allowance date is a key event, since the Notice of Patent Allowance provides an unambiguous and finalized statement of claims allowed by the patent office (claims which may be revised by the judicial system (Lemley and Shapiro, 2005)). ${ }^{17}$ We define the patent allowance lag as simply the patent allowance date less the patent application date, measured in months, and the post-allowance administrative lag as the patent grant date less the patent allowance date, also in months. While the mean of patent application date is in the early portion of 1991, the average patent grant date occurs at the end of 1993 (the average patent allowance lag is more than 32 months). Interestingly, the average post-allowance administrative lag is more than 6 months, and ranges from 1 to 19 months (with 60\% experiencing a 5-7 month administrative lag).

The central focus of our empirical analysis is the relative timing of technology licensing and patent allowance. Our remaining timing measures therefore depend on the licensing date. For each technology, the licensing date is the first publicly reported instance of licensing, as reported by the SDC database. We define the licensing lag to be equal to the time (in months) between patent application date and the licensing date $($ mean $=44.54)$. As well, we construct a dummy variable, post patent allowance, equal to one for those licenses recorded after the patent allowance date (mean $=0.73$ ), and a separate dummy variable, post patent grant, equal to one for those licenses recorded after the patent grant date $($ mean $=0.58)$. Figure $\mathrm{B}$ plots the distribution of the difference between patent allowance lag and licensing lag: data to the left of 0 are associated with licensing deals reached prior to patent allowance, while data to the right of 0 indicate post-allowance licensing. There seems to be a marked increase in the level of licensing for about a year from the patent allowance date. In other words, despite wide variation in both the patent allowance and licensing lag, there seems to be a striking linkage between the timing of patent allowance and licensing agreements.

\footnotetext{
${ }^{17}$ It is possible that communications prior to the Notice of Patent Allowance reduces uncertainty over claims prior to the patent allowance date. We investigate this by checking for an uptick in licensing prior to the patent allowance date. We also investigate whether the patent grant date has an additional impact beyond the patent allowance date. In an earlier draft, we focused exclusively on the patent grant date, where we observed a significant rise in licensing activity in the four months prior to the patent grant date. We thank an anonymous referee for this suggestion.
} 
As described in Table 1 and in more detail in Appendix A, our dataset also includes firm and patent characteristics. These measures allow us to evaluate the impact of observable measures of the business environment on licensing behavior. In terms of firm characteristics, we define dummies for locations that may provide access to different types of technology licensing networks (Silicon Valley, Route 128, and Canada), and proxies for firm experience and resources, including firm age and VC funded. We additionally construct four industry dummy variables: biotechnology, electronics, software, and scientific instruments sectors. Not only might the underlying timing of licensing differ significantly across industry sectors (and so we stratify the baseline hazard rate by industry), but the importance of patent allowance may also vary across industries. For example, patent allowance may be relatively unimportant in the software industry (where product cycle time is short and patents are either weak or copyright protection may serve as a substitute (Graham and Mowery, 2003; Lerner and Zhu, forthcoming), but more salient in biotechnology (where the product lifecycle is less rapid and where achieving effective tacit knowledge transfer may be particularly important). Finally, we include several patent characteristics in the analysis. From the NBER patent data file (Hall et al, 2001), we include patent claims, patent classes, patent citations made, patent backward citation lag, and patent originality. We also include the number of non-patent references to the scientific literature, science references, and the number of non-patent, non-scientific references, non-science references. These patent characteristics may be informative about the incentives for pre- versus post-allowance licensing, such as the importance of productive efficiency, the level of tacit knowledge, or patent scope, and so may influence the baseline hazard rate of licensing, or mediate the salience of patent allowance itself. As we discuss in some detail in Appendix A, the interpretation of each of these individual measures is subtle, and so we are therefore cautious in our interpretation of these measures.

Table 1B provides a tabulation of the patent allowance lag and licensing lag by industry. While electronics and scientific instruments are associated with a relatively short patent allowance lag (27 months), average allowance lags are much longer in biotechnology (38 months). While the licensing lag is also longest in biotechnology, software is associated with the shortest licensing lag (40 months). Whereas 
patent delay is shortest in the electronics industry, this industry is associated with the second longest licensing lag. This variation in both patent allowance lag and licensing lag leads to significant crossindustry variation in the share of licenses realized after patent allowance: while post allowance licensing occurs more than $80 \%$ of the time in electronics, less than two-third of software industry licenses occur prior to the patent allowance date. Patents seem to play different roles in different sectors; evaluating this claim systematically requires an analysis of how patent allowance date shifts the licensing hazard rate.

\section{The Empirical Framework}

Our objective is to identify the causal impact of patent allowance date (or patent grant date) on the timing of licensing behavior. The heart of the empirical strategy is to exploit the significant empirical variation in patent allowance and licensing lags across technologies, and the timing of licensing relative to patent allowance. For each technology, we structure the dataset into monthly observations from the patent application date, and define License $_{i t}$ equal to 0 for the period prior to the end of the licensing lag, and equal to 1 for the month in which the licensing lag ends (resulting in a unique absorbing event from the first license). We also define a time-varying regressor, Post-Patent ${ }_{i t}$, equal to 0 for months after the patent application date but prior to the patent allowance date, and equal to 1 after the patent allowance date. Since we observe a pre-patent and post-patent period for each innovation (and it is possible that licensing occurs prior to the post-patent period), our empirical objective is analogous to the estimation of the "treatment effect" of patent allowance date on the timing of licensing (Abbring and van den Berg, 2003). Here, we discuss our empirical specification for identifying this parameter, our approach to testing the key hypotheses, and the impact of our sample selection criteria on the interpretation of the estimates.

Our analysis employs a Cox proportional hazard rate model with time-varying regressors. The Cox model is specified as a continuous time hazard rate function, which incorporates a non-parametric baseline hazard rate and a multiplicative term allowing regressors to have a proportional impact relative to the baseline (Lancaster, 1990). Letting $h_{\text {license }}$ equal the hazard rate of license changing from 0 to 1 (i.e.,

the instantaneous probability of failure at $t$, conditional on survival until $t$ ), allowing for stratification by industry, and including controls for observable factors shifting the Cox hazard rate function: 
$h_{\text {LICENSE }}\left(t, \operatorname{POST}_{\operatorname{PATENT}}^{t}, l_{i}, Z_{i}\right)=h^{l_{i}}(t) \cdot \exp \left\{\beta_{0}+\beta_{Z} Z_{i}+\beta_{\text {POST PATENT }}\right.$ POST PATENT $\left._{i}^{t}\right\}$

where $l$ subscripts each industrial sector, and $Z$ includes firm, location, and patent characteristics. Under the assumption that (2) is the true model, $\beta_{\text {POST PATENT }}$ can be interpreted as the impact of patent allowance date on the licensing hazard rate. The identification of this parameter relies on variation in the patent allowance lag (if all technologies experienced the same patent allowance lag, we could not disentangle the impact of patent allowance date from the baseline hazard). However, unobserved heterogeneity makes identifying $\quad \beta_{\text {POSTPATENT }}$ challenging $\quad\left(h_{\text {LCENSE }}\left(t\right.\right.$, POST PATENT $\left._{i}^{t}, l, Z_{i}\right)$ $=h^{\prime}(t) \cdot \exp \left\{\beta_{0}+\beta_{z} Z_{i}+\beta_{\text {POST PATENT }}\right.$ POST PATENT $\left.\left._{i}^{t}+v_{i}\right\}\right)$, where $v_{i}$ is drawn from a distribution, $f(v)$, but is unobservable to the econometrician (van den Berg, 2001)). The presence of unobserved heterogeneity can result in bias if $v_{i}$ is correlated with the observables, in particular POST PATENT. For example, technologies with long patent allowance lags may tend to have low realizations of $v_{i}$, and so rather than a causal impact of patent allowance date on the licensing hazard, there may simply be a spurious correlation between the length of the patent allowance lag and the length of the licensing lag. However, as emphasized by Abbring and van den Berg (2003), the presence of unobserved heterogeneity does not necessarily undermine the identification of the impact of a "treatment effect" (in this case, $\beta_{\text {POST PATENT }}$ ). Whereas the value of $v_{i}$ impacts the hazard rate in all periods, POST PATENT only impacts the hazard rate after the patent allowance date. To exploit this insight, we take advantage of a relatively unique feature of our dataset: we observe patent allowance lag for all technologies, even those who "fail" (i.e., license) prior to the patent allowance date. We include patent allowance lag as a regressor in the hazard function, which controls for correlation between patent allowance lag and licensing lag, and focus on the change in the hazard after the patent allowance date ${ }^{18}$ $h_{\text {LICENSE }}\left(t, \mathrm{POST}_{\mathrm{PATENT}}^{t}, l, Z_{i}\right)=h^{l}(t) \cdot \exp \left\{\beta_{0}+\beta_{Z} Z_{i}+\beta_{\text {PATENILAG }} \mathrm{PATENT} \mathrm{LAG}_{\mathrm{i}}+\beta_{\text {POST PATENT }} \mathrm{POSTPATENT}_{i}^{t}+v_{i}\right\}$

As long as post patent is conditionally independent of $v_{i}$ (conditional on stratification by industry, $Z$, and

\footnotetext{
${ }^{18}$ Including patent lag as a linear term is arbitrary and experiments with a "control function" approach or a shared frailty parameter do not change the qualitative results (see the online Appendix D).
} 
patent allowance lag), the Cox regression coefficient on $\beta_{\text {POST PATENT }}$ can be interpreted as the impact of patent allowance date on the hazard of licensing (Abbring and van den Berg, 2003).

This framework provides a parametric test for our first hypothesis, and can be adapted to evaluate our supplementary hypotheses (see Appendix C). First, we can define a set of time-varying measures which will allow us to estimate coefficients to evaluate how the hazard rate is changing during time intervals as the patent allowance date approaches and during time intervals after patent allowance has occurred. According to the theory, there should be no effect or, at most, a modest effect as information is being revealed prior to the patent allowance date, followed by an enhanced licensing hazard rate, attenuating over time. Second, we can introduce several interaction terms between post patent allowance and measures of the strategic and technological environment. We de-mean each element of our control vector $Z_{i}$ (i.e., calculate $\bar{Z}$ ) to formulate a specification which allows us to estimate how the overall impact of patent allowance date on licensing changes with changes in the underlying economic, strategic, and technical environment. Third, we can distinguish whether the licensing hazard rate results from the patent allowance date or from the subsequent formal patent grant date.

\section{Empirical Results}

We are now ready to examine the hazard rate results. Table 2 presents our baseline Cox hazard regression results based on monthly data. In this and the following empirical tables, we present both the estimated coefficients as well as the implied hazard ratios (which should be read relative to one), since the latter makes the estimated size effects more apparent. The "failure" event in these regressions is the first instance of patent licensing. The first specification, (2-1), examines the impact of a post-allowance patent (without additional controls) on the hazard of licensing. The estimate is significant at the $1 \%$ level (all estimates are based on robust standard errors, clustered at the firm level), and implies that patent allowance is associated with more than a $200 \%$ increase in the underlying hazard rate. ${ }^{19}$ The second column of Table 2 adds the regressor patent allowance lag, which controls for the underlying correlation

\footnotetext{
${ }^{19}$ All findings are robust to either the patent allowance date or patent grant date as the key timing measure.
} 
between the pendency from patent application to allowance and licensing speed. This specification also allows each industry to have its own baseline hazard function (as an industry-stratified hazard model) and includes fixed effects for each patent application year. By allowing the industry hazard rate and the impact of patent application year to be freely estimated, our post patent allowance estimate is identified from within-industry variation of patent "cohorts." By controlling directly for the spurious correlation between patent allowance lags and licensing lags (due to potential unobserved features of the technology), and controlling for unobserved heterogeneity through stratification and application year fixed effects, we expect the absolute size of the post patent allowance coefficient to decline. Indeed, the size of the coefficient is reduced relative to (2-1); however, the estimated coefficient remains large and statistically significant (the notice of allowance increases the hazard rate by just under 70\%). As well, the coefficient on patent allowance lag is negative and highly significant, suggesting that longer patent allowance times are correlated with longer licensing lags. Together, these results suggest that while unobserved factors shaping the timing of licensing and patent allowance lags are important, patent allowance itself has an independent causal impact on the market for ideas. ${ }^{20}$ In the final specification in Table 2, we add one additional regressor, post patent grant. This allows us to examine whether the additional event of actually receiving the patent grant changes the hazard of licensing, above and beyond the patent allowance event. It does not. The post patent allowance coefficient remains large and significant. Hence, the probability of licensing is significantly enhanced when uncertainty surrounding formal IP rights is reduced.

Table 3 examines whether this core finding is robust to the inclusion of different controls. Each specification continues to include a complete set of patent application year fixed effects, industry-level stratification, and a control for patent allowance lag. We begin with firm characteristics. In (3-1), we include the three location variables (allowing us to explore whether licensing effects are different in technologically "networked" locales such as Silicon Valley and Route 128 (Saxenian, 1994)). (3-2) includes both firm age and $V C$ funded (thereby controlling for firm maturity, access to financial resources,

\footnotetext{
${ }^{20}$ Online Appendix D includes additional specifications exploring this baseline result, including the use of a control function approach, a shared frailty parameter, and a parametric distribution for the baseline hazard rate. The estimated coefficient on post patent allowance is larger in these specifications and remains statistically significant.
} 
and the potential for access to the $\mathrm{VC}$ network). While none of these control variables is individually significant (or even estimated to have a large impact), the underlying size and significance of the post patent allowance coefficient persists. We then include the complete set of measured patent characteristics in (3-3) and, finally, include all control variables in (3-4). In both of these specifications (as well as the additional robustness checks we discuss below), the coefficient on post patent allowance is remarkably stable, both in economic and statistical significance. In addition, two of the patent characteristic variables are significantly related to changes in the licensing hazard rate. A one standard deviation increase in patent backward citation lag is associated with more than a $25 \%$ reduction in the licensing hazard rate. This finding is consistent with the interpretations of Narin (1994) and Markewicz (2005), who suggest that higher backward citation lags may be associated with longer technology cycle times. Productive efficiency considerations may not be as important in such settings, resulting in a lower hazard. The coefficient on science references is also significant and positive (though the estimated magnitude is relatively small), and is consistent with Fleming and Sorenson's (2004) suggestion that science-intensive patents have a higher degree of technological transparency (and would thus involve a less complex licensing process). These patterns hold across a wide range of control structures and robustness checks. ${ }^{21}$

We now turn to our second hypothesis, and examine whether licensing behavior is "clustered" in the period immediately following patent allowance. To do so, we estimate an industry-stratified model with application-year specific fixed effects (similar to (2-3)). In place of the post patent allowance dummy variable, we estimate eight mutually exclusive time window dummies. ${ }^{22}$ Our results are presented in Figure C. In the eight months prior to the patent allowance date (which are estimated using two four

\footnotetext{
${ }^{21}$ We experimented with measures of technology "importance," including the forward citations to each patent. Since this measure may be endogenous (early licensing may induce higher number of forward citations), we do not include it in Table 3 (the results are similar and forward citations is insignificant). The results are also robust to various sub-samples: young firms (below the median sample age), "early" cohorts (applications before 1996), "late" cohorts (applications after 1990), using a time window to account for a "pre-announcement" effect (allowing the treatment three months prior to the actual allowance date), and excluding six patents that have undergone litigation.

${ }^{22}$ The windows are as follows: greater than 12 months prior to patent allowance (normalized to 1.0), 12 to 8 months prior to allowance, 7 to 4 months prior to allowance, 3 months to allowance, 1 to 4 months after allowance, 5 to 8 months after allowance, 9 to 12 months after allowance, and greater than 12 months after allowance. Because these time window dummies are exhaustive and mutually exclusive, we cannot separately estimate the impact of post patent allowance. We instead focus on the changes during the periods up to and after the allowance date.
} 
month time window dummies), there is a slight (statistically insignificant) increase in the licensing hazard rate. In contrast, during the two four month windows just after patent allowance, there is a dramatic spike in the licensing hazard (the hazard rate jumps more than $100 \%$ during these two periods). Thereafter, the hazard rate once again declines, stabilizing at a level of approximately 1.25 (relative to the baseline hazard). These effects are not simply a qualitative pattern. It is possible to reject the null hypothesis that the coefficient in the four months just after the patent allowance date is equal to earlier window coefficients. These results offer a significant refinement on our earlier analysis: not only does patent allowance have a permanent impact on the licensing hazard, but the effect also seems to be most salient in the period just after the patent allowance itself. Abbring and van den Berg (2003) suggest that a key piece of evidence for the "causal" impact of a treatment is whether the hazard rate increases significantly in the period immediately after the treatment (but not before). Figure $\mathrm{C}$ accords precisely with the intuition, suggesting a causal influence of patent allowance on the hazard rate of licensing.

Finally, we examine interaction effects between post patent allowance and patent and firm characteristics. While the interaction effects with industry dummies are modeled directly (i.e., Post Patent Allowance ${ }_{i}^{t}$. Industry $y_{i}$ ), the remainder of the interaction effects are defined as an interaction between post patent allowance and deviations from the sample means for each measure (i.e., Post Patent Allowance ${ }_{i}^{t} \cdot\left(Z_{i}-\bar{Z}\right)$ ). As such, the coefficient on post patent allowance (or post patent allowance * industry) can be interpreted as the effect when each of the interaction measures are set equal to their sample means. The first column of Table 4 examines the complete set of post patent allowance*industry interaction effects together with the regressor patent allowance lag. While the effect of post patent allowance is positive in all industries, patent allowance has a significant impact in the electronics and biotechnology industries, no statistically significant impact on licensing behavior in scientific instruments and only a negligible and noisy positive coefficient in the software industry. This pattern is consistent with key differences between these industries. In biotechnology, patent protection is extremely important and long regulatory lags may make productive efficiency concerns less important. 
Conversely, in the software industry, technology cycle times are very rapid, copyright protection offers a substitute mechanism for protecting IP in the context of licensing negotiations, and software patents themselves may be of uneven quality (e.g., Hall and MacGarvie, 2006).

The second column investigates interaction effects between patent allowance and firm location, age, and funding. The only significant interactions are with the Silicon Valley and Route 128 location dummies. While the direct effect of being located in Silicon Valley is an increase in the licensing hazard rate, patent allowance itself plays a much more muted role for Silicon Valley companies (and companies in the Route 128 area). Though there may be several explanations for this finding (e.g., the types of technologies developed in these locations may be different), these results are consistent with the hypothesis that the impact of formal intellectual property may be reduced in highly networked environments where licensees may be protecting their reputation in the market for ideas and brokers actively seek to facilitate the licensing process. In (4-3), we examine interactions between patent characteristics and post patent allowance. We find one effect in addition to the significant effects of patent backward citation lag and science references (as in Table 3). While the direct effect of patent classes is positive, the interaction between patent classes and post patent allowance is negative. Though we are cautious in our interpretation (several of the patent characteristic measures are correlated with each other), the direct patent classes effect is consistent with the hypothesis that technologies associated with a greater number of patent classes may be of interest to a wider range of potential licensees, but that the enforceability of patents with coverage across a wider number of classes is more uncertain. The coefficient on patent allowance lag * post patent allowance is small and insignificant, and so the impact of patent allowance does not seem to depend on the length of the patent allowance lag. The final specification includes all patent and firm characteristics, and a complete set of interaction effects. While several of the coefficients are noisier, the overall pattern of results remains: the impact of patent allowance is highest for the electronic equipment industry, and is lower for firms located in Silicon Valley 
and technologies that cover a wider range of patent classes. ${ }^{23}$

\section{Conclusions}

This paper considers the impact of delays in the granting of IP on the market for ideas. To the extent that patent allowance mitigates uncertainty regarding the scope of IP protection, delays in resolving that uncertainty may delay cooperative commercialization agreements. Among our sample of start-up innovators who ultimately reach a licensing agreement, the impact of patent allowance is associated with a $70 \%$ increase in the hazard rate of licensing, and this effect is most pronounced in the time period immediately following the patent allowance event. The results are also conditioned on the strategic and institutional environment in which firms operate. For technologies where productive efficiency effects are important, licensing is rapid. For technologies with alternative IP rights available (such as copyright), or firms in locations where information brokers and reputational mechanisms may be important (such as Silicon Valley), the impact of patent allowance on the licensing hazard rate is reduced. ${ }^{24}$

Our findings provide evidence for frictions in the market for ideas. Such frictions might arise from asymmetric information, search costs, or the challenges associated with transferring tacit knowledge from start-up innovators to potential licensees. While prior research suggested the role of formal IP in enabling the markets for ideas, the evidence presented here offers the first direct evidence that privatesector innovators are causally influenced by the receipt of IP rights. Patent allowance reduces the uncertainty of patent scope, and so reduces (though does not eliminate) imperfections in the market for

\footnotetext{
${ }^{23}$ We also examined whether the impact of patent allowance is changing over time by interacting post patent allowance with application year. The coefficient is small and not significant. We also explored whether the impact of patent allowance is changing over time differentially across industries. We did not identify any significant trends. Finally, we tested whether there was a change in the impact of patent allowance after the 1995 patent harmonization reforms (which dated patent terms from application rather than grant). We only observe 29 licenses with patent application dates after 1995, and so the results are noisy (the sign and magnitude vary depending on specification).

${ }^{24}$ Estimates from a parametric failure time model in the online Appendix (D-4) imply that for firms using the patent system to achieve a licensing agreement, patent allowance delay results in an 18-month average delay in licensing. Our analysis is conditioned on a sample of innovations receiving patents which are ultimately licensed, and so likely yields an upper bound on the population impact of the patent system on the market for ideas. Because some innovators never seek licenses for their technology, the population impact of patent allowance is equal to $\beta_{\text {POST }}$ PATENT multiplied by the share of innovators seeking licensing. Hsu (2006), using a broadly similar approach for identifying start-up innovators and examining a dataset of over 1,100 technology entrepreneurs, finds that $42 \%$ of start-up innovators receive at least one patent, and $15 \%$ of those firms commercialize through cooperation. Therefore, while the marginal impact of patent allowance is significant the overall start-up licensing rate is modest.
} 
ideas. The analysis highlights the value of grappling with the operational details of the patent system. It would also be interesting to identify the types of technologies or companies that are able to achieve cooperative commercialization outcomes in the absence of patent allowance. Our analysis also highlights the strategic tradeoff innovators face between the protection of their ideas and the pursuit of an effective commercialization strategy. While commercialization would often be enhanced by prompt and pervasive disclosure (perhaps including scientific journal publication, participation in standards-setting bodies, etc.), establishing protection against expropriation often requires delay and some level of secrecy. Since the market for ideas is imperfect, the disclosure strategy of the firm becomes crucial. A recent literature has begun to explore these issues, ranging from choices over when to publish or not in the scientific and technical literature, when to patent or not, and when to protect knowledge through tacit means or outright secrecy (e.g., Arora et al., 2001; Gittleman and Kogut, 2003). While this work begins to unpack some of the tradeoffs arising from disclosure and the use of an (imperfect) intellectual property and litigation system, we leave the formulation of an optimal disclosure strategy across the full range of strategic and institutional environments as an open question.

\section{References}

Abbring, J.H. and G.J. van den Berg. 2003. "The Nonparametric Identification of Treatment Effects in Duration Models.” Econometrica 71 1491-1518.

Aghion, P. and J. Tirole. 1994. “The Management of Innovation.” Quarterly J Econom. 109 1185-1210.

Anand, B. and T. Khanna. 2000. "The Structure of Licensing Contracts" Journal of Industrial Economics 48 103-135.

Anton, J.J. and D.A. Yao. 1994. "Expropriation and Inventions: Appropriable Rents in the Absence of Property Rights.” Amer. Econom. Rev. 84 190-209.

Arora, A. 1995. "Licensing Tacit Knowledge: Intellectual Property Rights and the Market for KnowHow", Econom. Innovation and New Technology 4 41-49.

Arora, A., A. Fosfuri, and A. Gambardella. 2001. Markets for Technology: The Economics of Innovation and Corporate Strategy. Cambridge, MA: MIT Press. 
Arora, A, M. Ceccagnoli, and W.M. Cohen. 2003. "R\&D and the Patent Premium," NBER paper 9431.

Arrow, K.J. 1962. "Economic Welfare and the Allocation of Resources for Inventions." In R. Nelson (ed.), The Rate and Direction of Inventive Activity: Economic and Social Factors. Princeton, N.J.: Princeton University Press.

Ausubel, L., P. Cramton and R.J. Deneckere. 2002. “Bargaining with Incomplete Information.” Handbook of Game Theory, Vol. 3, (R. Aumann and S. Hart, eds.), North-Holland: Amsterdam, Chapter 50.

Cohen, W.M. and Merrill, S.A. (eds.). 2003. Patents in the Knowledge-Based Economy, Washington, DC: National Academies Press.

Dechenaux, E., B. Goldfarb, S.A. Shane, M.C. Thursby. 2003. "Appropriability and the Timing of Innovation: Evidence from MIT Inventions," NBER paper 9735.

Elfenbein, D. 2004. "Publications, Patents and the Market for University Inventions," mimeo, Washington Univ.

Farrell, J. and C. Shapiro. 2007. "The Strength of Weak Patents," mimeo, Univ. of California, Berkeley.

Fleming, L. and O. Sorenson. 2004. "Science as a Map in Technological Research" Strategic Mgmt. J. 25 909-28.

Gans, J.S., D.H. Hsu and S. Stern. 2002. "When Does Start-up Innovation Spur the Gale of Creative Destruction?" RAND J. Econom. 33 571-86.

Gans, J.S. and Stern, S. 2000. "Incumbency and R\&D Incentives: Licensing the Gale of Creative Destruction," J. of Econom. Mgmt. Strategy 9 485-511.

Gittelman, M. and Kogut, B. 2003. "Does Good Science Lead to Valuable Knowledge? Biotechnology Firms and the Evolutionary Logic of Citation Patterns," Mgmt. Sci. 49 366-382.

Graham, S.J.H. and D. Harhoff. 2006. "Can Post-Grant Reviews Improve Patent System Design? A Twin Study of US and European Patents" CEPR paper 5680.

Graham, S.J.H. and D. Mowery. 2003. "Intellectual Property Protection in the US Software Industry," in Patents in the Knowledge-Based Economy, W.M. Cohen and S.L. Merrill, eds. Washington, DC: National Academies Press. 
Hall, B.H., A.B. Jaffe, and M. Trajtenberg. 2001. "The NBER Patent Citation Data File: Lessons, Insights and Methodological Tools," NBER paper 8498.

Hall, B.H. and M. MacGarvie. 2006. “The Private Value of Software Patents,” NBER paper 12195.

Harhoff, D. and S. Wagner. 2005. "Modeling the Duration of Patent Examination at the European Patent Office," CEPR paper 5283.

Heller, M. and R. Eisenberg. 1998. "Can Patents Deter Innovation? The Anti-commons in Biomedical Research," Science 280 698-701.

Hellmann, T. 2005. "The Role of Patents for Bridging the Science to Market Gap," mimeo, Univ. British Columbia.

Hsu, D. 2006. "Venture Capitalists and Cooperative Start-up Commercialization Strategy," Mgmt. Sci. 52 204-219.

Jaffe, A. and J. Lerner. 2004. Innovation and Its Discontents. Princeton, NJ: Princeton University Press.

Johnson, D.K.N. and D. Popp. 2003. "Forced Out of the Closet: The Impact of the American Inventors Protection Act on the Timing of Patent Disclosure," RAND J. Econom. 34 96-112.

Katila, R. and P.Y. Mang. 2003. "Exploiting Technological Opportunities: The Timing of Collaborations," Res. Policy 32 317-332.

Kitch, E. 1977. "The Nature and Function of the Patent System," J. Law and Econom. 20 265-290.

Lancaster, T. 1990. The Econometric Analysis of Transition Data, Cambridge: Cambridge Univ. Press.

Lanjouw, J.O. and M. Schankerman. 2001. "Characteristics of Patent Litigation: A Window on Competition," RAND J. Econom. 32 129-151.

Lanjouw, J.O. and M. Schankerman. 2004. "Patent Quality and Research Productivity: Measuring Innovation with Multiple Indicators,” Economic J. 114 441-465.

Lemley, M.A. and C. Shapiro. 2005. "Probabilistic Patents" J. Econom. Perspectives 19 75-98.

Lerner, J. and R. Merges. 1998. "The Control of Technology Alliances: An Empirical Analysis of the Biotechnology Industry," J. Industrial Econom. 46 125-156. 
Lerner, J. and F. Zhu. Forthcoming. "What is the Impact of Software Patent Shifts? Evidence from Lotus v. Borland," International J. Industrial Organ.

Lowe, R.A. 2004. "Knowledge Transfer and University Entrepreneurship,” mimeo, Carnegie Mellon Univ.

Markewicz, K.R. 2005. "University Patenting and the Rate of Knowledge Exploitation," mimeo, UC Berkeley.

Narin, F. 1994. "Patent Bibliometrics,” Scientometrics 30 147-55.

Nelson, R.R. and R. Merges. 1990. "On the Complex Economics of Patent Scope," Columbia Law Rev. 90 839-916.

Popp, D., T. Juhl and D. Johnson. 2004. “Time in Purgatory: Determinants of the Grant Lag for US Patent Applications," Topics in Economic Analysis \& Policy 4.

Quillen Jr., C.D. and O.H. Webster. 2001. "Continuing Patent Applications and Performance of the U.S. Patent Office," Federal Circuit Bar J. 11 1-21.

Saxenian, A. 1994. Regional Advantage: Culture and Competition in Silicon Valley and Route 128. Cambridge, MA: Harvard University Press.

Shapiro, C. 2001. "Navigating the Patent Thickets: Cross-Licenses, Patent Pools, and Standard-Setting," in J. Jaffe, J. Lerner, and S. Stern, eds., Innovation Policy and the Economy, NBER: Cambridge, MA.

Teece, D. 1986. "Profiting from Technological Innovation: Implications for Integration, Collaboration, Licensing and Public Policy." Res. Policy 15 285-305.

Van den Berg. 2001. "Duration Models: Specification, Identification, and Multiple Durations," Handbook of Econometrics, Vol. V, (J.J. Heckman and E. Leamer, eds.), North-Holland: Amsterdam.

Figure A: Uncertainty and the Patenting Process

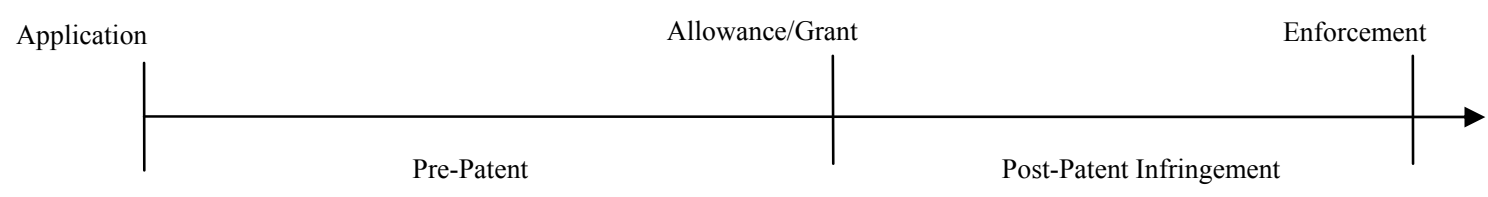

Figure B: Distribution of Difference between Patent Allowance and Licensing Dates 


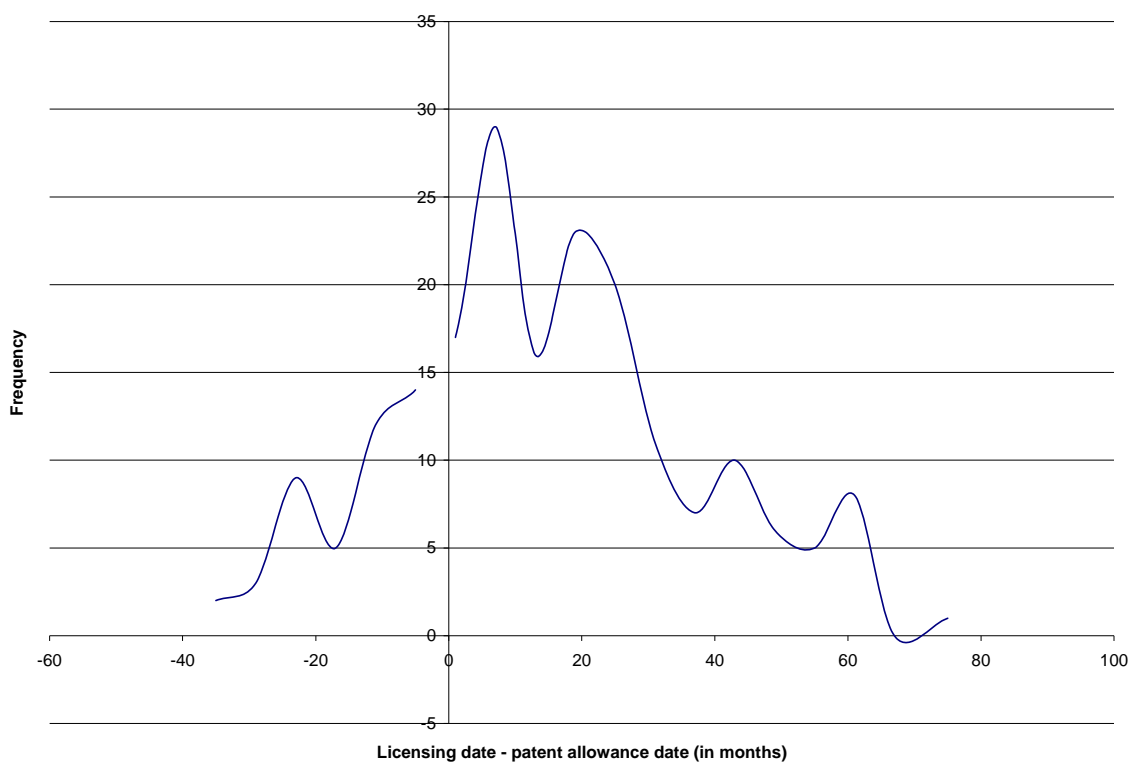

Figure C: Licensing Hazard Ratio, Pre- vs. Post-Patent Allowance

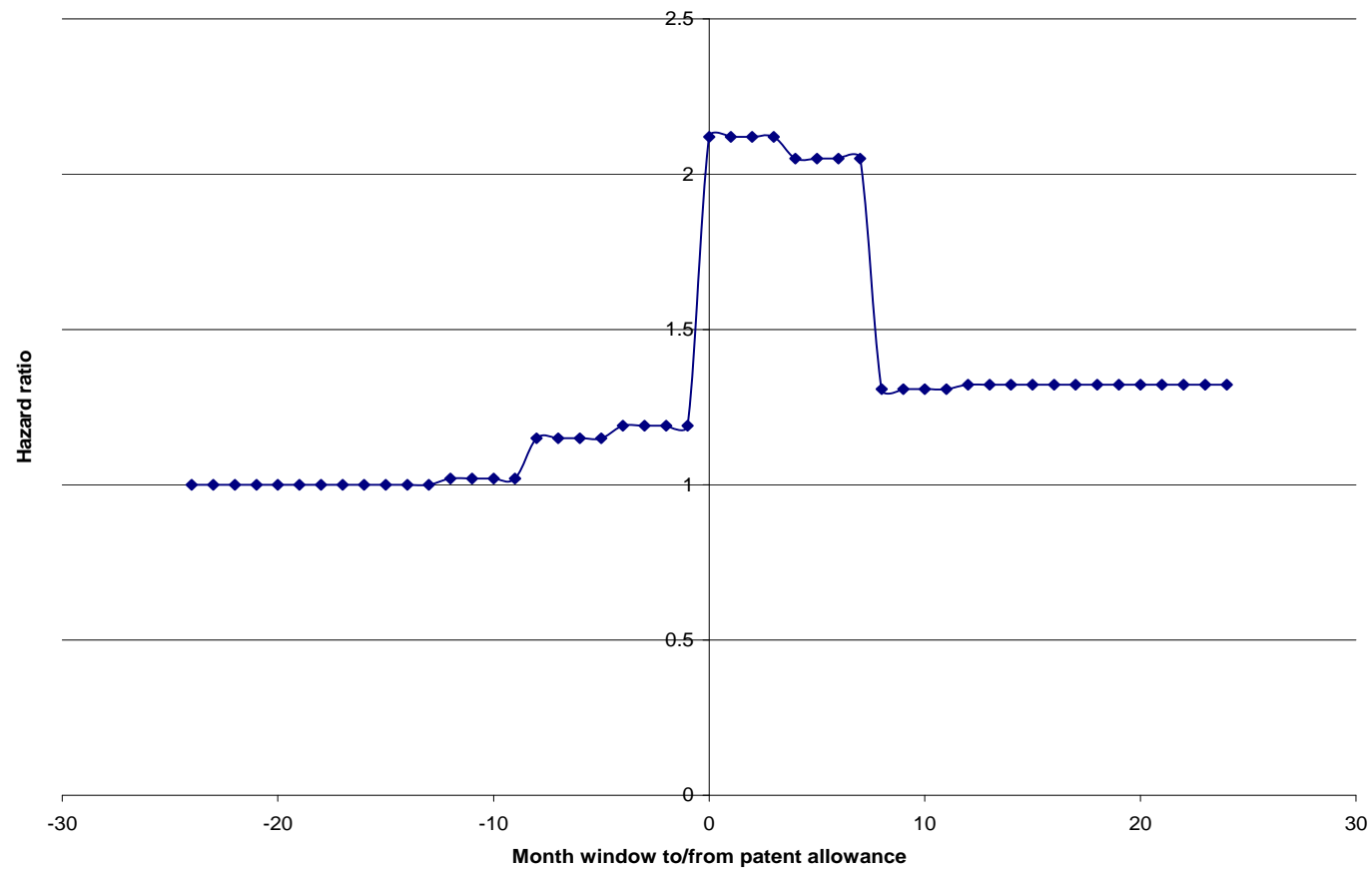


Table 1A

Variable Definitions, Means, and Standard Deviations

\begin{tabular}{|c|c|c|c|}
\hline VARIABLE & DEFINITION & MEAN & $\mathrm{SD}$ \\
\hline \multicolumn{4}{|l|}{ Timing Measures } \\
\hline Patent application date & Date of patent application & 1991.16 & 3.96 \\
\hline Patent allowance date & Date of USPTO notice of patent allowance & 1993.88 & 3.94 \\
\hline Patent grant date & Date of USPTO notice of patent grant & 1994.40 & 3.89 \\
\hline Licensing date & Date of patent licensing & 1994.95 & 3.47 \\
\hline Licensing lag & $\begin{array}{l}\text { Licensing date - Patent application date (in } \\
\text { months) }\end{array}$ & 44.54 & 26.46 \\
\hline Post patent allowance & $\begin{array}{l}\text { Dummy }=1 \text { if Licensing date }>\text { Patent allowance } \\
\text { date }\end{array}$ & 0.73 & 0.45 \\
\hline Post patent grant & Dummy $=1$ if Licensing date $>$ Patent grant date & 0.58 & 0.50 \\
\hline Patent allowance lag & $\begin{array}{l}\text { Months between patent allowance and patent } \\
\text { application }\end{array}$ & 32.58 & 20.18 \\
\hline $\begin{array}{l}\text { Post-allowance } \\
\text { administrative lag }\end{array}$ & Months between patent allowance and patent grant & 6.79 & 2.81 \\
\hline \multicolumn{4}{|l|}{ Patent Characteristics $^{*}$} \\
\hline Patent claims & $\#$ of claims made in the patent & 20.84 & 19.70 \\
\hline Patent citations made & $\#$ of patent citations referenced in the patent & 11.17 & 11.48 \\
\hline Patent classes & \# of 3-digit classes to which the patent is assigned & 1.90 & 1.07 \\
\hline $\begin{array}{l}\text { Patent backward citation } \\
\text { lag }\end{array}$ & $\begin{array}{l}\text { \# of years between patent grant and the average } \\
\text { grant year of backward citations }\end{array}$ & 7.54 & 4.32 \\
\hline Patent originality & $\begin{array}{l}1-\text { Herfindahl of referenced patent classes (based } \\
\text { on backward patent citations) }\end{array}$ & 0.43 & 0.27 \\
\hline Science references & $\begin{array}{l}\text { \# of non-patent references made in the patent to the } \\
\text { scientific literature }\end{array}$ & 7.56 & 16.75 \\
\hline Non-science references & $\begin{array}{l}\text { \# of non-patent references made in the patent to the } \\
\text { non-scientific literature }\end{array}$ & 2.40 & 5.44 \\
\hline \multicolumn{4}{|l|}{ Firm Characteristics } \\
\hline Firm age & Age of the firm in years & 6.03 & 6.68 \\
\hline VC funded & Dummy $=1$ if firm is funded by venture capital & 0.48 & 0.50 \\
\hline Silicon Valley & Dummy $=1$ if firm is located in Silicon Valley & 0.21 & 0.41 \\
\hline Route 128 & Dummy $=1$ if firm is located in Boston region & 0.12 & 0.33 \\
\hline Canada & Dummy $=1$ if the firm is located in Canada & 0.18 & 0.38 \\
\hline
\end{tabular}

* These data (with the exception of the last two) are from Hall, Jaffe, and Trajtenberg (2001).

Table 1B

Means of Timing Measures by Industry Sector

\begin{tabular}{|c|c|c|c|c|}
\hline & Biotechnology & Electronics & Software & Sci. Instruments \\
\hline \# observations & 82 & 44 & 35 & 37 \\
\hline Patent allowance & 38.34 & 27.32 & 31.51 & 27.05 \\
lag & $(21.66)$ & $(18.03)$ & $(12.67)$ & $(22.17)$ \\
\hline Licensing lag & 48.61 & 43.86 & 39.91 & 40.70 \\
& $(28.51)$ & $(26.33)$ & $(19.59)$ & $(27.16)$ \\
\hline Post patent & 0.70 & 0.80 & 0.66 & 0.78 \\
allowance & $(0.46)$ & $(0.41)$ & $(0.48)$ & $(0.42)$ \\
\hline
\end{tabular}


Table 2: Baseline Cox Hazards (Dependent Variable = LICENSE)

\begin{tabular}{|c|c|c|c|c|c|c|}
\hline \multirow[t]{2}{*}{ Independent Var. } & \multicolumn{2}{|c|}{$(2-1)$} & \multicolumn{2}{|c|}{$(2-2)$} & \multicolumn{2}{|c|}{$(2-3)$} \\
\hline & Haz. Ratio & Coef. & Haz. Ratio & Coef. & Haz. Ratio & Coef. \\
\hline Post patent allowance & $\begin{array}{l}3.241 * * * \\
(0.626)\end{array}$ & $\begin{array}{l}1.176^{* * * *} \\
(0.193)\end{array}$ & $\begin{array}{l}1.695 * * \\
(0.453) \\
\end{array}$ & $\begin{array}{l}0.528 * * \\
(0.267) \\
\end{array}$ & $\begin{array}{l}1.815^{* *} \\
(0.476)\end{array}$ & $\begin{array}{l}0.596 * * \\
(0.262)\end{array}$ \\
\hline Patent allowance lag & & & $\begin{array}{l}0.978 * * * \\
(0.005)\end{array}$ & $\begin{array}{l}-0.022 * * * \\
(0.005)\end{array}$ & $\begin{array}{l}0.976 * * * \\
(0.006)\end{array}$ & $\begin{array}{l}-0.025 * * * \\
(0.006)\end{array}$ \\
\hline Post patent grant & & & & & $\begin{array}{c}0.793 \\
(0.198)\end{array}$ & $\begin{array}{c}-0.231 \\
(0.250)\end{array}$ \\
\hline Patent App. Yr. FE & & & & & & \\
\hline Biotechnology & & & \multirow{3}{*}{\multicolumn{2}{|c|}{$\begin{array}{c}\text { hazard rate stratified by } \\
\text { industry }\end{array}$}} & \multirow{3}{*}{\multicolumn{2}{|c|}{$\begin{array}{l}\text { Hazard rate stratified by } \\
\text { industry }\end{array}$}} \\
\hline Electrical equipment & & & & & & \\
\hline Software & & & & & & \\
\hline Log likelihood & \multicolumn{2}{|c|}{-834.170} & \multicolumn{2}{|c|}{-537.620} & \multicolumn{2}{|c|}{-537.698} \\
\hline
\end{tabular}

$* *$ and $* * *$ indicate statistical significance at the $5 \%$ or $1 \%$ level, respectively. Robust standard errors are clustered by firm; $\mathrm{N}=8045$

Table 3: Baseline Industry-Stratified Cox Hazards with Controls (Dependent Variable $=$ LICENSE)

\begin{tabular}{|c|c|c|c|c|c|c|c|c|}
\hline \multirow[t]{2}{*}{ Independent Var. } & \multicolumn{2}{|c|}{ (3-1) } & \multicolumn{2}{|c|}{ (3-2) } & \multicolumn{2}{|c|}{$(3-3)$} & \multicolumn{2}{|c|}{ (3-4) } \\
\hline & Haz. Ratio & Coef. & Haz. Ratio & Coef. & Haz. Ratio & Coef. & Haz. Ratio & Coef. \\
\hline Post patent allowance & $\begin{array}{l}1.690 * * \\
(0.451)\end{array}$ & $\begin{array}{c}0.524 * * \\
(0.267)\end{array}$ & $\begin{array}{l}1.695 * * \\
(0.453)\end{array}$ & $\begin{array}{c}0.528 * * \\
(0.267)\end{array}$ & $\begin{array}{l}1.757 * * \\
(0.492)\end{array}$ & $\begin{array}{l}0.564 * * \\
(0.280)\end{array}$ & $\begin{array}{l}1.757 * * \\
(0.494)\end{array}$ & $\begin{array}{c}0.563 * * \\
(0.281)\end{array}$ \\
\hline Patent allowance lag & $\begin{array}{l}0.978^{* * * *} \\
(0.005)\end{array}$ & $\begin{array}{c}-0.022 * * * \\
(0.005)\end{array}$ & $\begin{array}{l}0.978 * * * \\
(0.005)\end{array}$ & $\begin{array}{l}-0.022 * * * \\
(0.005)\end{array}$ & $\begin{array}{l}0.973 * * * \\
(0.005)\end{array}$ & $\begin{array}{l}-0.028 * * * \\
(0.006)\end{array}$ & $\begin{array}{l}0.973 * * * \\
(0.006)\end{array}$ & $\begin{array}{l}-0.028 * * * \\
(0.006)\end{array}$ \\
\hline Silicon Valley & $\begin{array}{c}1.000 \\
(0.224)\end{array}$ & $\begin{array}{l}-0.000 \\
(0.224)\end{array}$ & & & & & $\begin{array}{c}0.992 \\
(0.226)\end{array}$ & $\begin{array}{l}-0.008 \\
(0.228)\end{array}$ \\
\hline Route 128 & $\begin{array}{c}1.107 \\
(0.251)\end{array}$ & $\begin{array}{c}0.102 \\
(0.226)\end{array}$ & & & & & $\begin{array}{c}1.069 \\
(0.271)\end{array}$ & $\begin{array}{c}0.067 \\
(0.253)\end{array}$ \\
\hline Canada & $\begin{array}{c}1.056 \\
(0.215)\end{array}$ & $\begin{array}{c}0.055 \\
(0.204)\end{array}$ & & & & & $\begin{array}{c}1.028 \\
(0.230)\end{array}$ & $\begin{array}{c}0.028 \\
(0.224)\end{array}$ \\
\hline VC funded & & & $\begin{array}{c}1.068 \\
(0.176)\end{array}$ & $\begin{array}{c}0.066 \\
(0.164)\end{array}$ & & & $\begin{array}{c}1.007 \\
(0.190)\end{array}$ & $\begin{array}{c}0.007 \\
(0.189)\end{array}$ \\
\hline Firm age & & & $\begin{array}{c}1.001 \\
(0.011) \\
\end{array}$ & $\begin{array}{c}0.001 \\
(0.011) \\
\end{array}$ & & & $\begin{array}{c}1.000 \\
(0.011) \\
\end{array}$ & $\begin{array}{c}0.000 \\
(0.011) \\
\end{array}$ \\
\hline Patent claims & & & & & $\begin{array}{c}1.003 \\
(0.003)\end{array}$ & $\begin{array}{c}0.003 \\
(0.003)\end{array}$ & $\begin{array}{c}1.002 \\
(0.003)\end{array}$ & $\begin{array}{c}0.002 \\
(0.003)\end{array}$ \\
\hline Patent classes & & & & & $\begin{array}{c}1.019 \\
(0.107)\end{array}$ & $\begin{array}{c}0.019 \\
(0.105)\end{array}$ & $\begin{array}{c}1.021 \\
(0.109)\end{array}$ & $\begin{array}{c}0.021 \\
(0.106)\end{array}$ \\
\hline Patent citations made & & & & & $\begin{array}{c}1.004 \\
(0.008) \\
\end{array}$ & $\begin{array}{c}0.004 \\
(0.008) \\
\end{array}$ & $\begin{array}{c}1.004 \\
(0.008) \\
\end{array}$ & $\begin{array}{c}0.004 \\
(0.008) \\
\end{array}$ \\
\hline $\begin{array}{l}\text { Patent backward citation } \\
\text { lag }\end{array}$ & & & & & $\begin{array}{l}0.937 * * * \\
(0.023)\end{array}$ & $\begin{array}{l}-0.065^{* * *} \\
(0.025)\end{array}$ & $\begin{array}{l}0.937 * * * \\
(0.023)\end{array}$ & $\begin{array}{l}-0.065^{* * *} \\
(0.025)\end{array}$ \\
\hline Patent originality & & & & & $\begin{array}{c}1.460 \\
(0.527)\end{array}$ & $\begin{array}{c}0.379 \\
(0.361)\end{array}$ & $\begin{array}{c}1.488 \\
(0.562)\end{array}$ & $\begin{array}{c}0.397 \\
(0.378)\end{array}$ \\
\hline Science references & & & & & $\begin{array}{l}1.011 * * * \\
(0.004)\end{array}$ & $\begin{array}{l}0.011 * * * \\
(0.004)\end{array}$ & $\begin{array}{l}1.011^{* *} \\
(0.005)\end{array}$ & $\begin{array}{l}0.011 * * \\
(0.005)\end{array}$ \\
\hline Non-science references & & & & & $\begin{array}{c}0.996 \\
(0.010)\end{array}$ & $\begin{array}{l}-0.004 \\
(0.010)\end{array}$ & $\begin{array}{c}0.996 \\
(0.011)\end{array}$ & $\begin{array}{l}-0.004 \\
(0.011)\end{array}$ \\
\hline Patent App. Yr.FE & Yes & & & & $\mathrm{Ye}$ & & $\mathrm{Ye}$ & \\
\hline Log likelihood & -537. & & -537 & & -527. & 16 & -527 & 890 \\
\hline
\end{tabular}

** and *** indicates statistical significance at the $5 \%$ and $1 \%$ levels, respectively. Robust standard errors are clustered by firm; $\mathrm{N}$ $=8045$. 
Table 4: Industry-Stratified Cox Hazards: Industry, Location \& Firm Interaction Effects (Dependent Variable $=$ LICENSE)

\begin{tabular}{|c|c|c|c|c|c|c|c|c|}
\hline \multirow[t]{2}{*}{ Independent Var. } & \multicolumn{2}{|c|}{$(4-1)$} & \multicolumn{2}{|c|}{$(4-2)$} & \multicolumn{2}{|c|}{$(4-3)$} & \multicolumn{2}{|c|}{$(4-4)$} \\
\hline & Haz. Ratio & Coef. & Haz. Ratio & Coef. & Haz. Ratio & Coef. & Haz. Ratio & Coef. \\
\hline Post patent allowance & & & $1.64 *(0.44)$ & $0.50 *(0.27)$ & $1.72 *(0.52)$ & $0.54 *(0.30)$ & & \\
\hline Patent allowance lag & $0.98 * * *(0.01)$ & $-0.02 * * *(0.01)$ & $0.98 * * *(0.01)$ & $-0.02 * * *(0.01)$ & $0.97 * * *(0.01)$ & $-0.03 * * *(0.01)$ & $0.97 * * *(0.01)$ & $-0.02 * * *(0.01)$ \\
\hline Biotech $*$ post pat. allowance & $1.78 *(0.61)$ & $0.57 *(0.35)$ & & & & & $1.54(0.70)$ & $0.43(0.45)$ \\
\hline Software * post patent allowance & $1.05(0.50)$ & $0.05(0.48)$ & & & & & $1.29(0.82)$ & $0.26(0.63)$ \\
\hline Electr. equip * post pat. allowance & $2.47 * *(1.13)$ & $0.91 * *(0.46)$ & & & & & $4.19 * * *(2.22)$ & $1.43 * * *(0.53)$ \\
\hline Sci. Instrum. * post pat. allowance & $1.68(1.05)$ & $0.52(0.62)$ & & & & & $1.28(0.85)$ & $0.25(0.67)$ \\
\hline Silicon Valley & & & $1.89 *(0.68)$ & $0.64 *(0.36)$ & & & $2.04 *(0.81)$ & $0.71 *(0.40)$ \\
\hline Route 128 & & & $1.82(0.68)$ & $0.60(0.37)$ & & & $1.35(0.63)$ & $0.30(0.47)$ \\
\hline Canada & & & $1.48(0.59)$ & $0.39(0.40)$ & & & $1.11(0.45)$ & $0.11(0.41)$ \\
\hline VC funded & & & $1.35(0.42)$ & $0.30(0.31)$ & & & $1.04(0.39)$ & $0.04(0.37)$ \\
\hline Firm age & & & $1.01(0.02)$ & $0.01(0.02)$ & & & $1.02(0.02)$ & $0.02(0.02)$ \\
\hline SV* post pat. allowance & & & $0.39 * *(0.18)$ & $-0.94 * *(0.46)$ & & & $0.41 *(0.20)$ & $-0.90 *(0.48)$ \\
\hline Rt. $128 *$ post pat. allow. & & & $0.44 *(0.22)$ & $-0.81 *(0.48)$ & & & $0.75(0.46)$ & $-0.28(0.61)$ \\
\hline Canada * post pat. allowance & & & $0.66(0.32)$ & $-0.41(0.48)$ & & & $0.91(0.43)$ & $-0.09(0.47)$ \\
\hline VC funded $*$ post pat. allowance & & & $0.76(0.27)$ & $-0.28(0.36)$ & & & $0.92(0.38)$ & $-0.08(0.42)$ \\
\hline Firm age * post patent allowance & & & $0.99(0.02)$ & $-0.01(0.02)$ & & & $0.97(0.03)$ & $-0.03(0.03)$ \\
\hline Patent claims & & & & & $1.00(0.01)$ & $0.00(0.01)$ & $1.00(0.01)$ & $0.00(0.01)$ \\
\hline Patent classes & & & & & $1.23 * *(0.12)$ & $0.21 * *(0.10)$ & $1.31 * * *(0.13)$ & $0.27 * * *(0.10)$ \\
\hline Patent citations made & & & & & $1.00(0.01)$ & $0.00(0.01)$ & $1.00(0.01)$ & $0.00(0.01)$ \\
\hline Patent backward citation lag & & & & & $0.86 * *(0.06)$ & $-0.15 * *(0.07)$ & $0.85 * *(0.06)$ & $-0.16 * *(0.07)$ \\
\hline Patent originality & & & & & $0.71(0.49)$ & $-0.34(0.69)$ & $1.49(0.56)$ & $-0.30(0.71)$ \\
\hline Science references & & & & & $1.01 *(0.01)$ & $0.01 *(0.01)$ & $1.01(0.01)$ & $0.01(0.01)$ \\
\hline Non-science references & & & & & $1.00(0.02)$ & $0.00(0.02)$ & $1.00(0.02)$ & $-0.00(0.02)$ \\
\hline Pat claims* post pat. allowance & & & & & $1.00(0.01)$ & $0.00(0.01)$ & $1.00(0.01)$ & $0.00(0.01)$ \\
\hline Pat classes $*$ post pat. allowance & & & & & $0.69 * *(0.12)$ & $-0.37 * *(0.17)$ & $0.64 * * *(0.11)$ & $-0.44 * * *(0.01)$ \\
\hline Pat cit. made* post pat. allowance & & & & & $1.00(0.02)$ & $0.00(0.02)$ & $1.00(0.02)$ & $0.00(0.02)$ \\
\hline Pat bkwd cit lag* post pat. allow & & & & & $1.11(0.08)$ & $0.10(0.07)$ & $1.12(0.08)$ & $0.12(0.07)$ \\
\hline Patent orig. ${ }^{*}$ post pat. allowance & & & & & $2.88(2.36)$ & $1.06(0.82)$ & $1.00(0.01)$ & $1.18(0.87)$ \\
\hline Science ref* post pat. allowance & & & & & $1.00(0.01)$ & $0.00(0.01)$ & $1.01(0.00)$ & $0.00(0.01)$ \\
\hline Non-sci ref* post pat. allowance & & & & & $0.99(0.02)$ & $-0.01(0.029)$ & $0.99(0.03)$ & $-0.01(0.03)$ \\
\hline Pat allow lag * post pat. allow & & & & & $1.00(0.01)$ & $0.00(0.01)$ & $1.00(0.01)$ & $0.00(0.01)$ \\
\hline Patent App. Yr. FE & & es & & es & & Yes & $\mathrm{Ye}$ & \\
\hline Log likelihood & -537 & 379 & -534. & 559 & -522 & .555 & -518. & 699 \\
\hline
\end{tabular}

$*, * *$ and $* * *$ indicates statistical significance at the $10 \%, 5 \%$, and $1 \%$ levels, respectively. Robust standard errors are clustered by firm; $\mathrm{N}=8045$. 


\title{
E-Companion to "The Impact of Uncertain Intellectual Property Rights on the Market for Ideas: Evidence from Patent Grant Delays"
}

\author{
Joshua S. Gans, David H. Hsu and Scott Stern
}

\section{Online Supplement}

This companion to the main paper provides addition detail associated with the data, empirical framework, and empirical results of the paper.

\section{APPENDIX A: Data Issues}

Sample Selection Criteria. We began by selecting all recorded deals in four sectors that are closely associated with cooperative commercialization between start-up innovators and more established industry players: biotechnology, electronics, software, and scientific instruments. Based on a reading of the deal description from the SDC database, we identified the first significant patent associated with the technology from searching the US Patent and Trademark Office (USPTO) website. This was done by searching patent titles and abstracts for key words taken from the SDC technology licensing activity description. This process yielded 219 patent-license pairs. By construction, our dataset excludes licenses for technologies in which no patent was ever issued, as well as technologies which are patented but never licensed. Beginning in November 2000, patent applications are disclosed 18 months after filing, as opposed to the time of patent grant (see Johnson and Popp (2003) for an analysis of the impact of the American Inventors Protection Act of 1999 (AIPA)). To impose uniformity regarding disclosure, and limit right-censoring, our sample covers the period prior to the AIPA.

While the overall analysis of deal structure across different types of players is extremely informative (e.g., Lerner and Merges, 1998), we focus our data sample in order to construct a clear test of our theoretical framework. Our sample is composed of licensing deals between start-up innovators and more established firms that are focused on specific technologies (rather than more general agreements involving long-term alliances or that are primarily focused on cross-licensing arrangements). From our initial database, we eliminate deals with the following characteristics: an established firm licensing to another established firm, an established firm licensing to a start-up, a non-profit entity as a licensor or licensee, renewal of a prior technology transfer agreement, and transactions involving strictly technology cross-licenses between or among parties. The deal was excluded if there was ambiguity over the match between the licensed technology and the patent associated with that technology or if the licensing date was earlier than the patent application date (the latter cause for exclusion may be related to the former). This process resulted in a final sample of 198 technologies for which a patent was issued a license was granted.

For a small set of observations (post-1999 patent grants), the HJT patent characteristics data are not available through the NBER file. We constructed the HJT measures for these observations, and checked whether our results are sensitive to their inclusion or exclusion. All qualitative results remain the same.

It is also useful to note that the industry coverage is distinct from the geography dummies over the dataset. Each of the industries is represented in each of the geographic regions (Silicon Valley, Route 128, Canada, and other), and the only significant pair-wise correlation between the industry and geography measures is a positive correlation between Route 128 and software $(\rho=0.20)$.

Firm and patent characteristics. Our dataset also includes firm and patent characteristics, allowing us to evaluate the impact of observable measures of the business environment on licensing behavior. First, we 
define dummy variables indicating locations that may provide access to different types of technology licensing networks: Silicon Valley, Route 128, and Canada. As key high-technology regions, firms located in Silicon Valley and Route 128 may experience a higher overall rate of technology licensing, as network-based mechanisms may facilitate exchange even in the absence of IPR, and so licensing may be less sensitive to patent allowance in these regions. Our sample also includes a relatively high number of Canadian licensing deals, and so we construct a Canada dummy (mean $=0.18$ ). We also include proxies for firm resources, experiences and capabilities. Firm age $($ mean $=6.03)$ is measured as of the patent application date, and a venture capital funding dummy, $V C$ funded (mean $=0.48$ ), only equals one for firms receiving venture funding prior to the patent application date. Access to a VC network, as well as increased maturity and reputation, might enhance the ability of a firm to engage in cooperative commercialization even in the absence of formal IPR (Hsu, 2006). Yet, firms with fewer organizational resources may be unable to delay licensing until patent allowance, and so may forego bargaining position to achieve an earlier licensing agreement. Younger firms may be less savvy in their approach to licensing, or may be willing to sacrifice bargaining power in order to quickly establish a cooperative commercialization agreement with an industry incumbent. While the overall effect of firm age or $V C$ funded on the timing of commercialization may therefore be ambiguous, inclusion of these measures in our empirical analysis allows us to control for the possibility that differences in experience or resources may be correlated with both the licensing lag and the patent allowance lag.

We also incorporate several patent characteristics in the analysis. Most of these measures are simply the standard measures from the Hall et al. (HJT, 2001) NBER data file. Patent claims is simply the number of claims allowed by the examiner (mean $=20.84$ ), while patent classes is the number of distinct primary three digit patent classes to which the patent is assigned (this measure ranges from 0-9; mean $=1.90$ ). Patent citations made is equal to the number of "backward" citations to prior patents (mean =11.17). Patent backward citation lag is the number of years between the patent grant date and the average grant year of those cited patents (mean $=7.56)$, and patent originality (mean $=0.43)$ measures the diversity of cited references (similar to a traditional Herfindahl index in which the measure ranges from zero to one, and is increasing in the uniformity of cited patent classes). We also include the number of non-patent references to the scientific literature (science references, mean $=7.56$ ) and the number of non-patent, non-scientific references (non-science references, mean $=2.40$ ). These patent characteristics may be informative about the incentives for pre- versus post-allowance licensing, such as the importance of productive efficiency, the level of tacit knowledge, or patent scope, and so may influence the baseline hazard rate of licensing, or mediate the salience of patent allowance itself. Of course, the interpretation of each measure is subtle (HJT, 2001; Lanjouw and Schankerman, 2004). Patent citations made may indicate a higher level of technological complexity (and therefore a higher level of tacit knowledge disclosure for effective commercialization), or alternately, a high level of this variable may be associated with significant uncertainty over the ultimate (enforceable) scope of a patent, since patent rights are more uncertain in the presence of a patent thicket (Shapiro, 2001). Similarly, while a higher level of patent claims, patent classes, or patent originality indicates a higher level of technological complexity and the likely importance of tacit knowledge, these measures may also be associated with increased patent scope (Lanjouw and Schankerman, 2001). While some authors argue that science references (and perhaps non-science references) indicate a higher degree of transparency for an invention (Fleming and Sorenson, 2004), Lowe (2004) suggests that patents including science references are more likely to require a high level of tacit knowledge transfer for effective 


\section{APPENDIX B \\ Timing Lag Distributions}
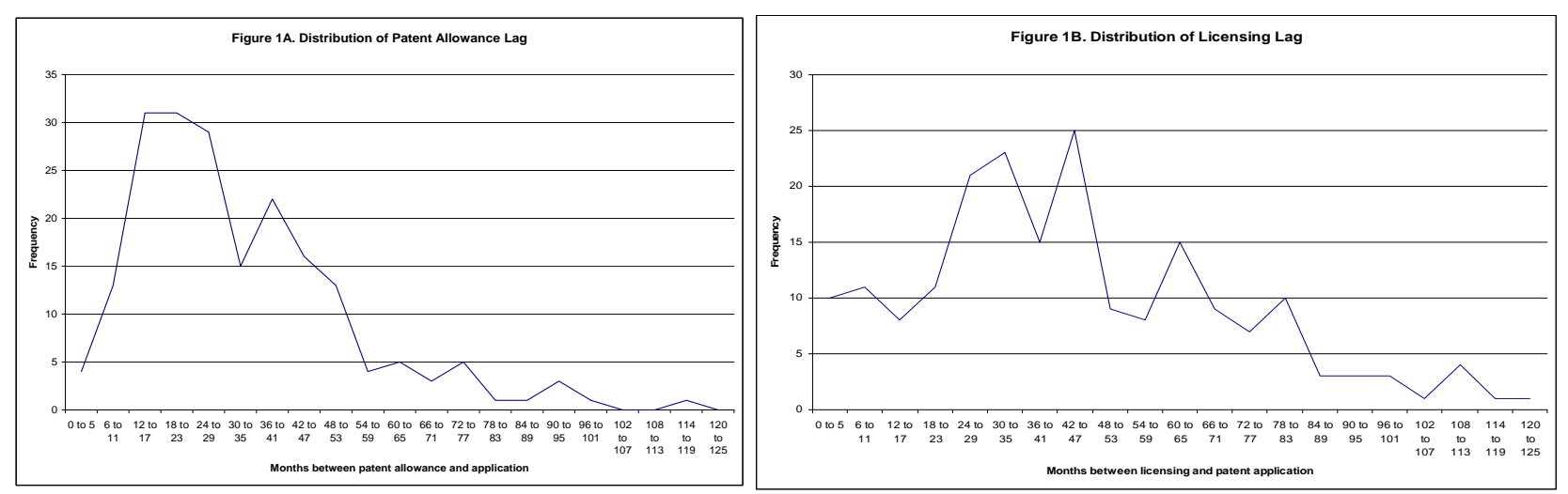

While only a very small number of technologies receive a patent allowance within a year of the application date, the majority of the technologies in our sample receive a patent allowance in the second, third, and fourth year after application. As well, the patent allowance lag has a large right tail, with a small number of technologies with patent allowance lags in excess of nine years. It is possible that extreme lags may be associated with technologies in which productive efficiency considerations may not be crucial; accordingly, we have experimented extensively with imposing a maximum patent allowance lag (e.g., 60 months). None of our key qualitative findings are affected.

In contrast to the patent allowance lag distribution, licensing lag is more evenly distributed. Figure 2 in the text of the main paper combines these histograms in reporting the distribution of licensing lag less patent allowance lag. Finally, it is useful to note that if we plot the histogram of licensing date less patent grant date (rather than patent allowance date), there is a pronounced increase in the rate of licensing in the four to six months prior to the patent grant date, which peaks in the first few months after the patent grant date. This is consistent with the fact that managers respond to the event associated with uncertainty reduction (the patent allowance date) rather than the date at which formal rights commence and the patent grant is published. 


\section{APPENDIX C: The Empirical Framework}

In our discussion of the empirical framework, we discuss but do not present the precise specifications for the tests of our supplementary hypotheses. First, to evaluate whether licensing is "clustered" immediately after the patent allowance date, we define a set of "window" variables (pre patent allowance $(k, l)$ and post patent allowance $(k, l)$ ), equal to 1 from $k$ to $l$ months prior to (or after) the patent allowance date, and 0 otherwise:

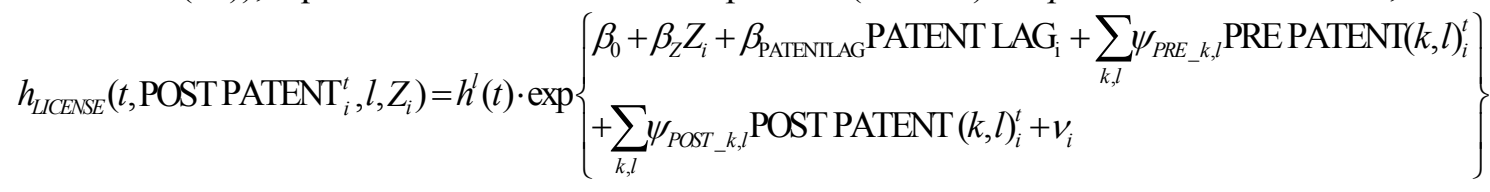

Second, we introduce several interaction terms between post patent allowance and measures of the strategic and technological environment. To do so, we de-mean each element of our control vector $Z_{i}$ (i.e., calculate $\bar{Z}$ ) to formulate the following hazard model:

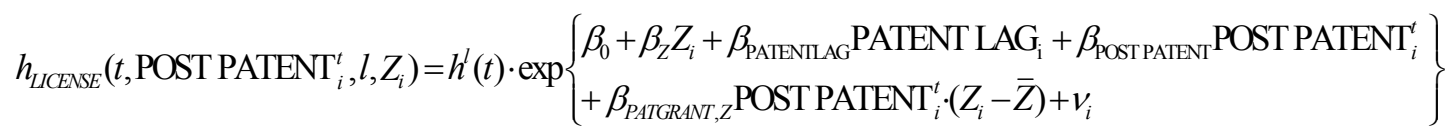

This allows us to estimate the overall impact of patent grant date on licensing and how this changes with changes in the underlying economic, strategic, and technical environment.

Finally, it is possible to incorporate multiple time-varying regressors and to distinguish whether the key "shock" to the licensing hazard rate results from the patent allowance date or from the subsequent formal patent grant date, as follows:

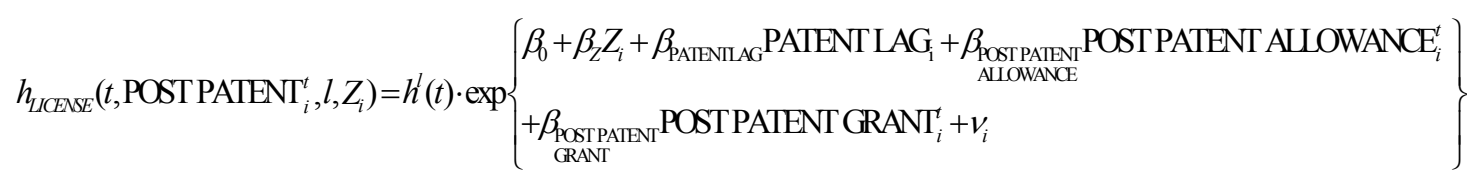




\section{APPENDIX D}

Robustness to Functional Forms and Estimation Methods

Dependent Variable $=$ LICENSE

(Robust standard errors are clustered by firm)

$$
\mathbf{N}=\mathbf{8 0 4 5}
$$

\begin{tabular}{|c|c|c|c|c|c|c|c|}
\hline \multirow[t]{3}{*}{ Independent Var. } & \multicolumn{2}{|c|}{ (D-1) } & \multicolumn{2}{|c|}{ (D-2) } & \multirow{2}{*}{\multicolumn{2}{|c|}{$\begin{array}{l}\text { (D-3) } \\
\begin{array}{l}\text { Shared gamma frailty Cox } \\
\text { regression }\end{array} \\
\end{array}$}} & \multirow{3}{*}{$\begin{array}{c}\text { (D-4) } \\
\text { Weibull-distributed failure time } \\
\text { Coef. }\end{array}$} \\
\hline & \multicolumn{4}{|c|}{ Cox proportional hazard models } & & & \\
\hline & Haz. Ratio & Coef. & Haz. Ratio & Coef. & Haz. Ratio & Coef. & \\
\hline Post patent allowance & $\begin{array}{l}3.026^{* * * *} \\
(0.667)\end{array}$ & $\begin{array}{l}1.107 * * * \\
(0.220)\end{array}$ & $\begin{array}{l}1.751 * * \\
(0.474)\end{array}$ & $\begin{array}{l}0.560 * * \\
(0.271)\end{array}$ & $\begin{array}{l}3.298 * * * \\
(0.666)\end{array}$ & $\begin{array}{l}1.216^{* * *} \\
(0.202)\end{array}$ & $\begin{array}{l}0.859 * * * \\
(0.244)\end{array}$ \\
\hline $\begin{array}{l}\text { Inverse of patent allowance } \\
\text { lag }\end{array}$ & $\begin{array}{c}15.059 \\
(31.972) \\
\end{array}$ & $\begin{array}{c}2.712 \\
(2.123) \\
\end{array}$ & $\begin{array}{c}1.501 \\
(4.276)\end{array}$ & $\begin{array}{l}0.406 \\
(2.849) \\
\end{array}$ & & & \\
\hline $\begin{array}{l}\text { Square of patent allowance } \\
\text { lag }\end{array}$ & & & $\begin{array}{c}1.000 \\
(0.000)\end{array}$ & $\begin{array}{l}-0.000 \\
(0.000) \\
\end{array}$ & & & \\
\hline Patent allowance lag & & & $\begin{array}{c}0.994 \\
(0.021)\end{array}$ & $\begin{array}{l}-0.006 \\
(0.022)\end{array}$ & & & $\begin{array}{l}-0.012 * * * \\
(0.004)\end{array}$ \\
\hline Patent App. Yr. FE & & & & & & & Yes \\
\hline Log likelihood & -544 & & & & -799 & & -157.177 \\
\hline
\end{tabular}

$* *$ and $* * *$ indicates statistical significance at the $5 \%$ and $1 \%$ levels, respectively.

This table includes a number of additional empirical specifications exploring the robustness of the baseline results in Table 2 . In the spirit of a control function approach, (D-1) and (D-2) include alternative functional forms for the treatment of the patent allowance lag (including the inverse (D-1) and the inclusion of the inverse, level and square of patent allowance lag (D-2)). In (D-3), we allow for "shared frailty" among technologies with similar patent allowance lags (we allow for 13 separate groupings based on six-month allowance lag windows and assume a gamma distribution), and in (D-4), we experiment with a specific functional form (Weibull) for the baseline hazard rate. In each of these alternative specifications, the estimated coefficient on post patent allowance remains large and statistically significant; indeed, the estimated impact of post patent allowance is actually higher for each these alternative assumptions and control structures than the coefficients reported in Table 2. 